\title{
Article \\ Red-Emitting Polymerizable Guanidinium Dyes as Fluorescent Probes in Molecularly Imprinted Polymers for Glyphosate Detection
}

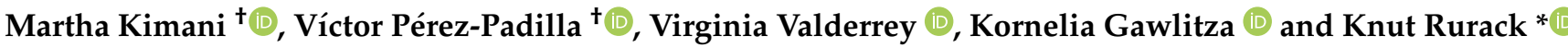 \\ Chemical and Optical Sensing Division, Bundesanstalt für Materialforschung und-prüfung (BAM), \\ Richard-Willstätter Straße 11, 12489 Berlin, Germany; martha-wamaitha.kimani@bam.de (M.K.); \\ victor.perez-padilla@bam.de (V.P.-P.); virginia.valderrey-berciano@bam.de (V.V.); \\ kornelia.gawlitza@bam.de (K.G.) \\ * Correspondence: knut.rurack@bam.de \\ † These authors contributed equally to this work.
}

check for

updates

Citation: Kimani, M.; Pérez-Padilla,

V.; Valderrey, V.; Gawlitza, K.; Rurack,

K. Red-Emitting Polymerizable

Guanidinium Dyes as Fluorescent

Probes in Molecularly Imprinted

Polymers for Glyphosate Detection.

Chemosensors 2022, 10, 99 .

https: / / doi.org/10.3390/

chemosensors10030099

Academic Editors: Francesco

Canfarotta and Marloes Peeters

Received: 18 January 2022

Accepted: 1 March 2022

Published: 3 March 2022

Publisher's Note: MDPI stays neutral with regard to jurisdictional claims in published maps and institutional affiliations.

Copyright: (C) 2022 by the authors. Licensee MDPI, Basel, Switzerland. This article is an open access article distributed under the terms and conditions of the Creative Commons Attribution (CC BY) license (https:// creativecommons.org/licenses/by/ $4.0 /)$.

\begin{abstract}
The development of methodologies to sense glyphosate has gained momentum due to its toxicological and ecotoxicological effects. In this work, a red-emitting and polymerizable guanidinium benzoxadiazole probe was developed for the fluorescence detection of glyphosate. The interaction of the fluorescent probe and the tetrabutylammonium salt of glyphosate was studied via UV/vis absorption and fluorescence spectroscopy in chloroform and acetonitrile. The selective recognition of glyphosate was achieved by preparing molecularly imprinted polymers, able to discriminate against other common herbicides such as 2,4-dichlorophenoxyacetic acid (2,4-D) and 3,6-dichloro-2-methoxybenzoic acid (dicamba), as thin layers on submicron silica particles. The limits of detection of $4.8 \mu \mathrm{M}$ and $0.6 \mu \mathrm{M}$ were obtained for the sensing of glyphosate in chloroform and acetonitrile, respectively. The reported system shows promise for future application in the sensing of glyphosate through further optimization of the dye and the implementation of a biphasic assay with water/organic solvent mixtures for sensing in aqueous environmental samples.
\end{abstract}

Keywords: glyphosate; guanidinium receptors; fluorescent probes; molecularly imprinted polymers; core-shell particles

\section{Introduction}

Globally, glyphosate (GPS) is the most widely used herbicide, its use increasing exponentially after the introduction of glyphosate-resistant transgenic crops in 1996 [1-3] In the past decade, therefore, interest in methods for its determination in environmental samples has grown because of its toxicological [4] and ecotoxicological effects [5,6], as well as its occurrence in water reserves and food [7]. In 2015, the International Agency for Research on Cancer classified GPS as "probably carcinogenic to humans" [4]. Thus, the development of methodologies to detect GPS has gained relevance in recent years, especially with respect to approaches that are reasonably simple and cost-effective, and that are potentially suitable for use outside of a dedicated laboratory and closer to an actual point of need, enabling preventive action [8].

GPS is a dimensionally small, linear, aliphatic molecule bearing three protic groups, a carboxylic acid, a phosphonic acid and an amino group (Scheme 1) [9]. 

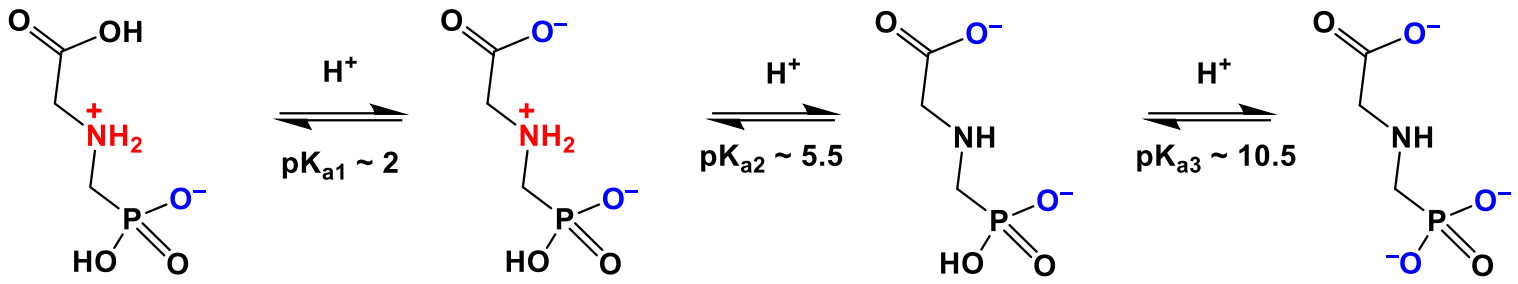

Scheme 1. Polyprotic acid-base equilibria of glyphosate in aqueous media, adopted from [9]; the implications on species diversity and $\mathrm{pK}_{\mathrm{a}}$ values are discussed in Section 3.

GPS is, thus, highly polar; it does not show sizable absorption or fluorescence in the $\mathrm{UV} / \mathrm{vis}$ spectral range and remains charged over a broad $\mathrm{pH}$ range in aqueous environments, rendering its detection and analysis using common approaches more complex [10]. Presently, GPS is mainly analyzed via liquid chromatography and/or mass spectrometry $[11,12]$, but derivatization is commonly required to enhance solubility in the organic solvents used for analysis and/or to equip GPS with a detectable tag, such as a fluorescent label. Derivatization, however, is time-consuming and can potentially lead to undesired by-products [11]. In terms of the quest for mobile analytical approaches, the previously listed methods require a laboratory environment. More suitable approaches for onsite analysis would be the use of optical or electrochemical detection techniques $[13,14]$. For colorless, non-fluorescent and redox-inactive analytes, such methods are usually realized in such a way that the analyte interacts or reacts with a probe, indicator, or mediator, thus modulating the latter's spectroscopic or redox behavior. Whereas electrochemical detection is in most cases indirect, the direct photoluminescence detection of GPS has been achieved by utilizing carbon dots [15-18], quantum dots [19,20], gold nanomaterials [21-24], or various other nanoparticles [25-27] with luminescence emission of between 350 and $615 \mathrm{~nm}$. However, reports are scarce regarding the detection of GPS with fluorescent molecular probes $[14,28,29]$, although the latter is perhaps the most straightforward way of directly translating a binding event of a small molecule into a measurable signal, allowing for sensitive detection [28,29]. Moreover, of these few reports, only Pouessel et al., as well as Jenkins et al., who co-imprinted luminescent $\mathrm{Eu}^{3+}$ with GPS into a polystyrene matrix, use the direct supramolecular binding of GPS [30,31]; the other works use indirect displacement approaches [14,32]. In principle, GPS, with its high number of functional groups in a small molecule, should be well-suited for being targeted via supramolecular chemistry approaches. However, the challenge that remains is connected to the fact that the supramolecular recognition and signaling of carboxylic and phosphonic acids, the terminal groups in GPS, rely on hydrogen bonding, yet GPS is virtually insoluble in organic solvents. The quest was, thus, to design a molecular recognition and indication system that bridges this apparent gap.

In terms of realizing an optical assay for GPS, fluorescent molecular probes that emit in the red or near infra-red (NIR) spectral range, exhibiting sizeable Stokes shifts to separate excitation and emitted light by simple instrumental means, as well as showing enhanced binding to oxoanions would be ideal. Typically, such probes utilize urea- and thiourea-binding motifs that rely on hydrogen bonding [33,34]. However, the strength of such interactions is significantly weakened in highly polar solvents. To improve the recognition ability of oxoanion probes in polar sensing media, organic guanidiniums can be used as alternative binding motifs in fluorescent probes. Guanidiniums bind oxoanions through strong salt-bridge-assisted hydrogen bonds, and this interaction has also been intensively studied in aqueous environments [35-38]. However, even if favorable interaction is accomplished, such probes are not able to discriminate between various carboxylic or phosphonic acids that are naturally present in many samples. When ultimately aiming at straightforward onsite analysis, which commonly does not allow for complicated separation steps, an element endowing the system with selectivity is thus additionally required. A promising approach in this regard is the strategy of molecular imprinting, which becomes particularly attractive when polymerizable fluorescent probe derivatives 
are covalently integrated into a polymer network, thus combining target selectivity through a tailored network with the indication ability of a potent probe molecule $[39,40]$. Recently, several molecularly imprinted polymers (MIPs) have been developed for the detection of GPS, where these MIPs have been applied for the extraction, preconcentration and sample clean-up of GPS and its analogs from aqueous samples [41,42]. Additionally, MIPs have also been reported for the electrochemical sensing of GPS [43,44]. However, to the best of our knowledge, no direct optical detection for GPS has been realized using MIPs so far.

In this work, a polymerizable fluorescent guanidinium probe was developed and incorporated into few-nanometric MIP coatings on submicron carrier particles for the selective recognition of GPS, allowing its determination in the $\mu \mathrm{M}$ concentration range in highly polar organic solvents. The reported system shows promise for future application in the sensing of GPS through further optimization of the dye and/or through the implementation of a biphasic assay with water/organic solvent mixtures for sensing in aqueous environmental samples.

\section{Materials and Methods}

\subsection{Materials}

All organic solvents were purchased from Sigma Aldrich (Taufkirchen, Germany), Acros Organics (Geel, Belgium), abcr (Karlsruhe, Germany), Merck (Darmstadt, Germany) or J.T. Baker/Fisher Scientific (Schwerte, Germany), and were used without further purification unless otherwise indicated. Analytical grade GPS, hexamethyldisilazane (>99\%), analytical grade 3,6-dichloro-2-methoxybenzoic acid (dicamba), 2,4-dichlorophenoxyacetic acid (2,4-D), tetrabutylammonium hydroxide (TBA-OH) $1 \mathrm{M}$ methanol solution, tetraethyl orthosilicate (TEOS), 32\% ammonia solution in water, (3-aminopropyl)triethoxysilane (APTES), methacrylamide (MAAm), ethylene glycol dimethacrylate (EGDMA) and aluminum oxide type 5016A basic (particle size 50-200 $\mu \mathrm{m})$ were obtained from Sigma Aldrich/Merck. Benzoyl isothiocyanate (98\%) and $N$-(3-dimethylaminopropyl)- $N^{\prime}$-ethylcarbodiimide hydrochloride $(\geq 98.0 \%)$ were purchased from ChemPur (Karlsruhe, Germany). Triethylamine and 37\% hydrochloric acid were obtained from AppliChem (Darmstadt, Germany). In addition, 4-cyano-4(phenylcarbonothioylthio)pentanoic acid (CPDB) was purchased from abcr. Ethyl chloroformate was purchased from Fluka/Sigma Aldrich (Buchs, Switzerland) and 2,2'-azobis(2,4-dimethylvaleronitril) (ABDV) initiator from Wako Chemicals (Neuss, Germany). Methylphosphonic acid (MPA) was obtained from Alfa Aesar (Karlsruhe, Germany). Milli-Q water was obtained from a Milli-Q ultrapure water purification system (Millipore Synthesis A10, Merck).

2.2. Synthesis of Benzamido((7)(2(methacrycrykoyloxy)ethyl)amino)benzo[c][1,2,5]-oxadiazol-4yl)amino)methaniminium chloride (I)

As recently described by us [45], 2-((7-aminobenzo[c][1,2,5]oxadiazol-4-yl)(methyl) amino)ethyl methacrylate $(0.50 \mathrm{~g}, 1.81 \mathrm{mmol})$ was dissolved in acetone $(5.0 \mathrm{~mL})$ before benzoyl isothiocyanate $(0.25 \mathrm{~mL}, 1.81 \mathrm{mmol})$ was added. The solution was stirred at room temperature and a red precipitate was formed. The precipitate was filtered, and 2((7-(3-benzoylureido)benzo[c][1,2,5]oxadiazol-4-yl)(methyl)amino)ethyl methacrylate was obtained as a red solid $(0.72 \mathrm{~g}, 90 \%$ yield $) .{ }^{1} \mathrm{H} \mathrm{NMR}\left(400 \mathrm{MHz}, \mathrm{CDCl}_{3}\right): \delta(\mathrm{ppm})=8.53$ $(\mathrm{d}, 1 \mathrm{H}), 7.95(\mathrm{~d}, 2 \mathrm{H}), 7.67(\mathrm{t}, 1 \mathrm{H}), 7.56(\mathrm{t}, 2 \mathrm{H}), 6.15(\mathrm{~d}, 1 \mathrm{H}), 5.88(\mathrm{~s}, 1 \mathrm{H}), 5.47(\mathrm{~s}, 1 \mathrm{H}), 4.43(\mathrm{t}, 2 \mathrm{H})$, $4.31(\mathrm{t}, 2 \mathrm{H}), 3.24(\mathrm{~s}, 3 \mathrm{H}), 1.88(\mathrm{~s}, 3 \mathrm{H}) .{ }^{13} \mathrm{C}-\mathrm{NMR}\left(100 \mathrm{MHz}, \mathrm{CDCl}_{3}\right): \delta(\mathrm{ppm})=176.68,167.05$, $166.88,146.88,144.97,136.72,135.79,133.76,131.46,129.19,127.56,125.88,125.19,113.96$, 104.64, 62.58, 52.84, 40.07, 18.13. High-resolution mass spectrometry (HRMS) $\left(\mathrm{ESI}^{+}\right): \mathrm{m} / z$ calculated for $\mathrm{C}_{21} \mathrm{H}_{22} \mathrm{~N}_{5} \mathrm{O}_{4} \mathrm{~S}([\mathrm{M}+\mathrm{H}])^{+} 440.1392$, found $([\mathrm{M}+\mathrm{H}])^{+} 440.1441$. UPLC: retention time $\left(t_{R}\right)=4.41 \mathrm{~min}(100 \%$ peak area $)$. The thiourea intermediate product $(0.40 \mathrm{~g}, 0.91 \mathrm{mmol})$ and $N$-(3-dimethylaminopropyl)- $N^{\prime}$-ethylcarbodiimide hydrochloride $(0.89 \mathrm{~g}, 4.55 \mathrm{mmol})$ were dissolved in a mixture of dry acetonitrile $(\mathrm{MeCN})(15 \mathrm{~mL})$ and $\mathrm{CH}_{2} \mathrm{Cl}_{2}(6 \mathrm{~mL})$. Afterward, hexamethyldisilazane $(2.12 \mathrm{~mL}, 9.10 \mathrm{mmol})$ was added dropwise at $0{ }^{\circ} \mathrm{C}$ and the 
reaction mixture was stirred overnight at room temperature. The solution was diluted with ethyl acetate (EtOAc, $100 \mathrm{~mL}$ ) and the organic phase was washed thrice with deionized water $(100 \mathrm{~mL})$. The organic phases were collected, dried over $\mathrm{MgSO}_{4}$ and concentrated in a vacuum. The reaction mixture was then purified by silica column chromatography, with a mixture of $\mathrm{CH}_{2} \mathrm{Cl}_{2}$ :EtOAc (9:1) as the mobile phase to give a red solid intermediate, 2-((7-(3-benzoylguanidino)benzo[c][1,2,5]-oxadiazol-4-yl)(methyl)amino)ethyl methacrylate $(0.34 \mathrm{~g}, 88 \%$ yield $) .{ }^{1} \mathrm{H}-\mathrm{NMR}\left(400 \mathrm{MHz} \mathrm{CDCl}_{3}\right)$ (Figure $\left.\mathrm{S} 1\right): \delta(\mathrm{ppm})=8.07(\mathrm{~d}, 2 \mathrm{H}), 7.51$ $(\mathrm{t}, 1 \mathrm{H}), 7.44(\mathrm{t}, 2 \mathrm{H}), 7.09(\mathrm{~d}, 1 \mathrm{H}), 6.10(\mathrm{~d}, 1 \mathrm{H}), 5.89(\mathrm{~s}, 1 \mathrm{H}), 5.47(\mathrm{~m}, 1 \mathrm{H})$, $4.42(\mathrm{t}, 2 \mathrm{H}), 4.29(\mathrm{t}, 2 \mathrm{H}), 3.21(\mathrm{~s}, 3 \mathrm{H}), 1.81(\mathrm{~s}, 3 \mathrm{H}) .{ }^{13} \mathrm{C}-\mathrm{NMR}\left(100 \mathrm{MHz}, \mathrm{CDCl}_{3}\right)$ (Figure S2): $\delta(\mathrm{ppm})=174.91,167.22,156.70,147.99,145.77,136.46,136.33,136.03,131.95,128.50$, 128.37, 126.71, 125.97, 116.10, 105.60, 62.84, 52.96, 40.30, 18.28. HRMS (ESI ${ }^{+}$) (Figure S5): $\mathrm{m} / \mathrm{z}$ calculated for $\mathrm{C}_{21} \mathrm{H}_{23} \mathrm{~N}_{6} \mathrm{O}_{4}([\mathrm{M}+\mathrm{H}])^{+}$423.1703. Found $([\mathrm{M}+\mathrm{H}])^{+}$423.1843. UPLC: $\mathrm{t}_{\mathrm{R}}=1.38 \mathrm{~min}(100 \%$ peak area $)$. This intermediate $(0.05 \mathrm{~g}, 0.12 \mathrm{mmol})$ was suspended in $\mathrm{HCl}(15 \mathrm{~mL}, 1 \mathrm{M})$ by means of ultrasonication. The reaction mixture was stirred overnight at room temperature, followed by dilution with $10 \mathrm{~mL}$ of $\mathrm{H}_{2} \mathrm{O}$. The aqueous phase was then extracted thrice with $\mathrm{CH}_{2} \mathrm{Cl}_{2}(20 \mathrm{~mL})$. The organic phases were collected, dried over $\mathrm{Na}_{2} \mathrm{SO}_{4}$, and concentrated in a vacuum. Compound I was obtained as a yellow solid (0.046, $84 \%$ yield). ${ }^{1} \mathrm{H}-\mathrm{NMR}\left(400 \mathrm{MHz}, \mathrm{CDCl}_{3}\right)$ (Figure S3): $\delta(\mathrm{ppm})=8.42(\mathrm{~d}, 2 \mathrm{H}), 7.68(\mathrm{t}, 1 \mathrm{H}), 7.58$ $(\mathrm{t}, 2 \mathrm{H}), 7.44(\mathrm{~d}, 1 \mathrm{H}), 6.13(\mathrm{~d}, 1 \mathrm{H}), 5.93(\mathrm{~s}, 1 \mathrm{H}), 5.52(\mathrm{~m}, 1 \mathrm{H}), 4.45(\mathrm{t}, 2 \mathrm{H}), 4.34(\mathrm{t}, 2 \mathrm{H}), 3.29(\mathrm{~s}$, $3 \mathrm{H}), 1.83(\mathrm{~s}, 3 \mathrm{H}) .{ }^{13} \mathrm{C}-\mathrm{NMR}\left(100 \mathrm{MHz}, \mathrm{CDCl}_{3}\right)$ (Figure S4): $\delta(\mathrm{ppm})=169.52,167.14,155.41$, $147.03,145.53,139.52,135.89,134.75,132.33,130.28,129.29,129.26,126.25,105.90,103.79$, 62.76, 53.33, 40.90, 18.30. HRMS (ESI ${ }^{-}$) (Figure S6): $\mathrm{m} / \mathrm{z}$ calculated for $\mathrm{C}_{21} \mathrm{H}_{22} \mathrm{~N}_{6} \mathrm{O}_{4} \mathrm{Cl}$ $([\mathrm{M}-\mathrm{H}])^{-} 457.1469$, found $([\mathrm{M}-\mathrm{H}])^{-} 457.1371$. UPLC: $\mathrm{t}_{\mathrm{R}}=2.13 \mathrm{~min}(100 \%$ peak area).

\subsection{Template Preparation with TBA-OH}

GPS or MPA were dissolved in $500 \mu \mathrm{L}$ of water in a 2-mL Eppendorf tube, with 10 min of sonication. Briefly, 2,4-D or dicamba were dissolved in $500 \mu \mathrm{L} \mathrm{MeCN}$ in a 2-mL Eppendorf tube with $10 \mathrm{~min}$ of sonication. To the solutions, an equimolar amount of $1 \mathrm{M}$ TBA-OH solution in methanol was added. The mixtures were sonicated for another $10 \mathrm{~min}$, then placed in a vacuum concentrator and dried in a vacuum overnight to give the corresponding templates.

\subsection{MIP Synthesis in $\mathrm{CHCl}_{3}$ and $\mathrm{MeCN}$}

The inhibitor was removed from EGDMA before polymerization by passing through a column packed with basic alumina. First, $0.8 \mathrm{mg}$ I $(1.72 \mu \mathrm{mol})$ and $4.4 \mathrm{mg}$ MAAm $(51.7 \mu \mathrm{mol})$ were dissolved in $5 \mathrm{~mL} \mathrm{MeCN}$ or $\mathrm{CHCl}_{3}$. Then, $48.9 \mu \mathrm{L}$ of EGDMA $(259.5 \mu \mathrm{mol})$ was added to each mixture, and sonication was performed for $5 \mathrm{~min}$. Then, $2 \mathrm{~mL}$ each of both solutions were added to brown glass vials, each containing $30 \mathrm{mg}$ of reversible-addition fragmentation chain transfer (RAFT) agent modified $\mathrm{SiO}_{2}$ particles (RAFT@SiO ${ }_{2}$ ), see Sections 2-6, Supplementary Material [46]. At this point, 0.3 mg GPSTBA $(0.69 \mu \mathrm{mol})$ and $0.2 \mathrm{mg}$ MPA-TBA $(0.69 \mu \mathrm{mol})$ (to serve as a "dummy" template for the "dummy" NIPs or dNIPs) were separately dissolved in $100 \mu \mathrm{L} \mathrm{MeCN}$ or $\mathrm{CHCl}_{3}$. These template solutions were added to separate vials containing the particles and the suspensions were sonicated for $5 \mathrm{~min}$. Then, $6 \mathrm{mg}$ ABDV $(24.1 \mu \mathrm{mol})$ was dissolved in $3.6 \mathrm{~mL} \mathrm{MeCN}$ or $\mathrm{CHCl}_{3}$ and $0.9 \mathrm{~mL} \mathrm{ABDV}$ solution was added to each vial. Thereafter, the suspensions were degassed for $10 \mathrm{~min}$ with argon under ice, then heated to $50{ }^{\circ} \mathrm{C}$ with mixing at $700 \mathrm{rpm}$ for $24 \mathrm{~h}$. The temperature was then increased to $70{ }^{\circ} \mathrm{C}$ for $2 \mathrm{~h}$, after which the particles were precipitated with $3 \mathrm{~mL} \mathrm{MeCN}$. The MIPs and dNIPs were then washed three times with $2 \mathrm{~mL}$ of MeCN and underwent centrifugation at $10,000 \times g$ for $5 \mathrm{~min}$, with $5 \mathrm{~min}$ of sonication between each wash. The particles with MIP or dNIP shells on $\mathrm{SiO}_{2}$ particles, $\mathbf{M I P a} @ \mathrm{SiO}_{2}, \mathbf{M I P b} @ \mathrm{SiO}_{2}, \mathbf{d N I P a} @ \mathrm{SiO}_{2}$ and $\mathbf{d N I P b} @ \mathrm{SiO}_{2}$ (where "a" denotes preparation in $\mathrm{CHCl}_{3}$ and " $\mathrm{b}$ " denotes preparation in $\mathrm{MeCN}$ ), were then dried overnight in a vacuum. 


\subsection{Instrumentation}

${ }^{1} \mathrm{H}$ and ${ }^{13} \mathrm{C}$ NMR spectra were recorded on a Mercury 400 NMR spectrometer (Varian, Darmstadt, Germany) for synthesis characterization and on a VNMRS 500 NMR spectrometer (Varian) for ${ }^{1} \mathrm{H}$ NMR titrations; mass spectra were obtained on an Acquity UPLC (Waters, Eschborn, Germany) with an LCT Premier XE time-of-flight mass detector (Waters) mass spectrometer. Transmission electron microscope (TEM) images were registered using a Talos F200S (200 kV) (Thermo Fisher Scientific, Dreieich, Germany). UV/vis absorption spectra were recorded on a Specord 210 Plus spectrophotometer (Analytik Jena, Jena, Germany). Steady-state fluorescence measurements were carried out on a FluoroMax-4P spectrofluorometer (Horiba Jobin-Yvon, Bensheim, Germany). Standard $10 \mathrm{~mm}$ path length quartz cuvettes were used for dye and particle titrations, while circular $100 \mu \mathrm{m}$ path length cuvettes were used to record pre-polymerization spectra using front-face geometry. Zeta potential measurements were performed with a Zetasizer Nano ZS (Malvern Panalytical, Kassel, Germany). Thermogravimetric analyses (TGA) were carried out on a STA7200 (Hitachi High-Tech Analytical Science Uedem, Germany) thermobalance, using in a first step, a nitrogen atmosphere $\left(80 \mathrm{~mL} \mathrm{~min}{ }^{-1}\right)$ with a heating program consisting of a ramp of $10^{\circ} \mathrm{C}$ $\min ^{-1}$ from $25^{\circ} \mathrm{C}$ to $600{ }^{\circ} \mathrm{C}$, and, in a second step, an oxidant atmosphere (air, $80 \mathrm{~mL} \mathrm{~min}^{-1}$ ) from $600{ }^{\circ} \mathrm{C}$ until $1000{ }^{\circ} \mathrm{C}$, with a heating program consisting of a ramp of $10{ }^{\circ} \mathrm{C} \mathrm{min}{ }^{-1}$. Elemental analysis measurements were performed on a Carbon/Sulfur Analyzer CS-800 (Eltra, Haan, Germany). BET isotherm data was acquired by $\mathrm{N}_{2}$ adsorption/desorption on an ASAP 2010 instrument (Micromeritics, Unterschleißheim, Germany).

\subsection{Particle Characterization}

For TEM measurements, $1 \mathrm{mg} \mathrm{mL}{ }^{-1}$ particle suspensions were prepared in $\mathrm{CHCl}_{3}$ or $\mathrm{MeCN}$, with $9 \mu \mathrm{L}$ of this mixture placed on a copper grid and left to dry. Images were analyzed with ImageJ software (National Institutes of Health and the Laboratory for Optical and Computational Instrumentation) [47]. To determine the diameter of the particles, data from 100 particles were collected, and the average and standard deviation of the measurements were calculated. To determine MIP and dNIP shell thickness, data from 20 particles were collected, and the average and standard deviation of the measurements were calculated.

For zeta potential determination, $0.04 \mathrm{mg} \mathrm{mL}^{-1}$ particle suspensions were prepared in Milli-Q water ( $\mathrm{pH} \mathrm{6)}$ and the zeta potential was measured using disposable folded capillary cells.

For fluorescence titrations, $1.0 \mathrm{mg} \mathrm{mL}^{-1}$ suspensions of the MIP and dNIP particles were prepared in $\mathrm{MeCN}$ or $\mathrm{CHCl}_{3}$. For titrations with $\mathbf{M I P a} @ \mathbf{S i O}_{2}, \mathbf{d N I P a} @ \mathbf{S i O}_{2}$ and $\mathbf{M I P b} @ \mathbf{S i O}_{2}, \mathbf{d N I P b} @ \mathrm{SiO}_{2}, 1$ mM solutions of GPS-TBA, 2,4 D-TBA and dicamba-TBA were prepared in $\mathrm{CHCl}_{3}$ and $\mathrm{MeCN}$, respectively. Increasing volumes of the template solutions were added to $2 \mathrm{~mL}$ suspensions of the MIP and dNIP particles; after 2 min of mixing for equilibration, the resultant fluorescence spectra were recorded. Subsequently, $\frac{\Delta F}{F_{0}}=\frac{F_{x}-F_{0}}{F_{0}}$ was calculated for each fluorescence spectrum of the MIP and dNIP (where $F_{x}$ is the fluorescence intensity at a certain wavelength for each spectrum after template addition, while $F_{0}$ is the fluorescence intensity at the respective wavelength before the addition of the template). The imprinting factors (IF) were determined from the MIP:dNIP ratio of $\frac{\Delta F}{F_{0}}$ at the saturation point of the titration. The discrimination factors (DF) were determined from the ratio of $\frac{\Delta F}{F_{0}}$ for GPS-TBA versus the competing template at the saturation point of the titration.

\section{Results}

The great majority of the current approaches target GPS with fluorescence assays relying on luminescent probes, irrespective of whether those are dyes or nanoparticles. These approaches have either used displacement assays, partly involving dye or quencher displacement, partly particle aggregation $[15,16,18,19,21,26,27]$, competitive formats $[17,20,22,25]$, or rather complex assay architectures $[23,24]$, which are all not only 
indirect but also do not allow for sensing of the analyte-once the dye/quencher has been displaced, or competitive binding has occurred, the test cannot be easily reused. Because our aim is to move toward the direct sensing of GPS, we embarked on the development of a GPS-selective fluorescent probe that also fulfills the application-oriented requirements of absorption in the visible spectral range and a strongly Stokes-shifted emission in the red-to-NIR range, so that instrumentation can be kept simple. In contrast to what has been previously realized in the few direct approaches, for instance, with a photoinduced electron transfer-type probe in the UV/vis region [30], we thus elaborated our concept of dimensionally small charge transfer (CT)-type fluorescent probe monomers [48] and integrated a second electron-donating unit into the fluorophore architecture, arriving at compound I (Figure 1a). CT processes guarantee well-separated bands and analyte-induced spectral shifts, which are beneficial for optical sensing in the context just mentioned.

(a)

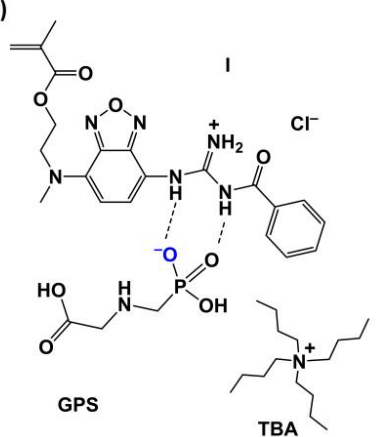

(b)

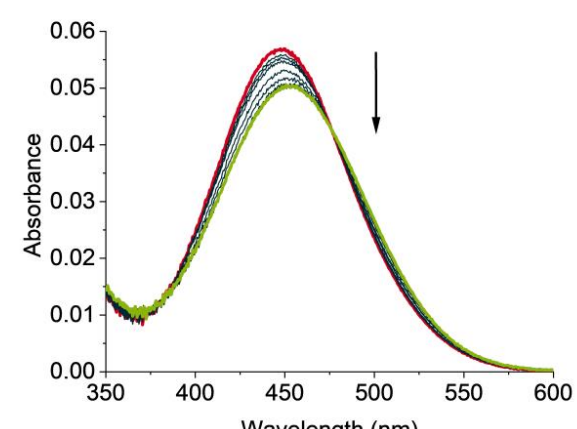

(d)

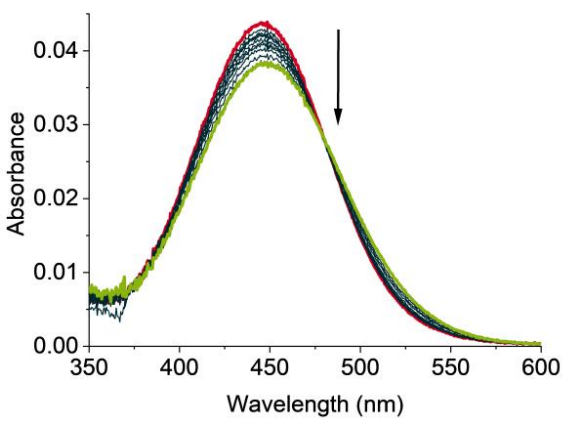

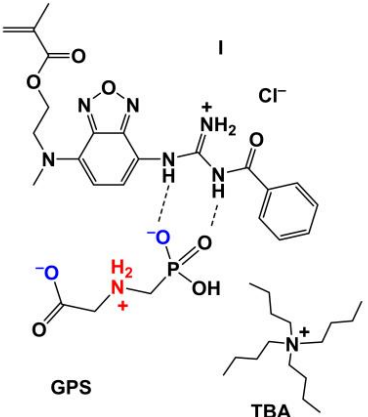

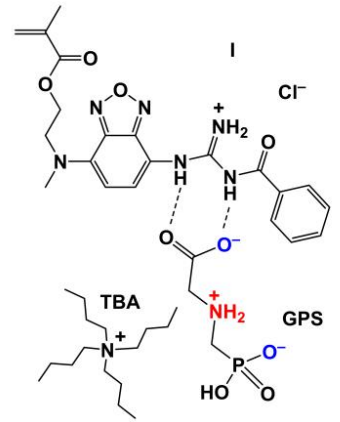

(c)
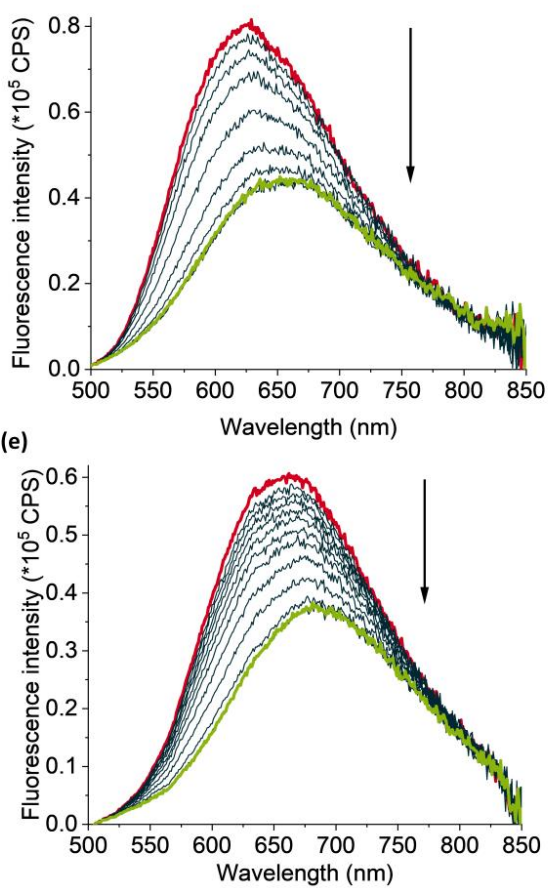

Figure 1. (a) Proposed major (left) and other possible (middle, right) species of GPS-TBA and the respective hydrogen bonding interactions between I and GPS-TBA in organic solvents; color code as in Scheme 1. (b) Absorption and (c) fluorescence emission spectra $\left(\lambda_{\mathrm{ex}}=474 \mathrm{~nm}\right)$ of $\mathbf{I}(6.5 \mu \mathrm{M})$ upon titration with GPS-TBA in $\mathrm{CHCl}_{3}(0.6-9.2 \mu \mathrm{M})$. The red line is the spectrum of $\mathbf{I}$ in $\mathrm{CHCl}_{3}$, while the green line shows the spectrum of I after the addition of 1.4 equivalents of GPS-TBA. (d) Absorption and (e) fluorescence spectra $\left(\lambda_{\mathrm{ex}}=483 \mathrm{~nm}\right)$ upon titration of $\mathbf{I}(6.5 \mu \mathrm{M})$ with GPS-TBA in MeCN $(0.1-9.9 \mu \mathrm{M})$. The red line is the spectrum of $\mathbf{I}$ in $\mathrm{MeCN}$, while the green line shows the spectrum of $\mathbf{I}$ after the addition of 1.5 equivalents of GPS-TBA. 


\subsection{Interaction of I with GPS-TBA in $\mathrm{CHCl}_{3}$ and $\mathrm{MeCN}$}

Compound I is a donor-acceptor-donor (push-pull-push)-substituted fluorescent molecular probe, designed to show a CT character upon optical excitation. It thus presents broad absorption bands (Figures 1 and S7) centered at $446 \mathrm{~nm}$ and $444 \mathrm{~nm}$, with a full width at half-maximum (FWHM) of $87 \mathrm{~nm}$ and $84 \mathrm{~nm}$ in $\mathrm{CHCl}_{3}$ and acetonitrile $(\mathrm{MeCN})$, respectively. Consequently, the fluorescence emission bands of I, centered at $622 \mathrm{~nm}$ and $652 \mathrm{~nm}$, are broad as well (Figures 1 and S7) with FWHM of $154 \mathrm{~nm}$ and $163 \mathrm{~nm}$ in $\mathrm{CHCl}_{3}$ and $\mathrm{MeCN}$, respectively. Thus, the dye exhibits desirable emission maxima in the red spectral range in the two solvents investigated. In addition, the Stokes shifts of $176 \mathrm{~nm}$ and $208 \mathrm{~nm}$ that were obtained for $\mathbf{I}$ in $\mathrm{CHCl}_{3}$ and $\mathrm{MeCN}$ suggest that the absorption and fluorescence bands are well-separated, which is desirable as it increases signal-to-noise ratios and reduces self-quenching [49]. In photophysical terms, after employing the empirical $\lambda^{2}$ correction for the fluorescence spectra [50], the Stokes shifts amount to 6700 and $7470 \mathrm{~cm}^{-1}$.

The guanidinium binding unit of I operates through salt bridge-assisted hydrogen bonding (Figure 1a). Direct $\pi$-conjugation of the binding unit to the fluorophore guarantees that such a binding of the analyte is transduced into a spectroscopic response. Accordingly, the interaction of I with oxoanions results in a decrease and a bathochromic shift of both the absorption and the emission spectra.

Guanidinium receptors have been widely used as sensing moieties for oxoanions via a hydrogen bonding mechanism, which is favored in organic solvents [51-54].

GPS is a polyprotic acid carrying different ionizable groups (carboxylic acid, amino, phosphonic acid). Although there is still a debate about the different structures and conformations involved in the de/protonation equilibria, as well as the absolute $\mathrm{p} K_{\mathrm{a}}$ data, recent studies suggest that the order of successive deprotonation of net neutral GPS is: carboxylate $\left(\mathrm{p} K_{\mathrm{a} 1}=1.6-2.4\right)$, amino $\left(\mathrm{p} K_{\mathrm{a} 2}=5.2-6.0\right)$, phosphonate $\left(\mathrm{p} K_{\mathrm{a} 3}=9.7-11.0\right)[9,54,55]$. When GPS is dissolved in water, anionic and zwitterionic structures are thus formed. It is also known that GPS is able to form strong hydrogen bonds in the solid state, which renders it insoluble in organic solvents [55]. Thus, tetrabutylammonium hydroxide (TBA-OH) was chosen as the auxiliary reagent for obtaining GPS-TBA in water without the presence of other anions, which is then readily soluble in organic solvents after drying. To keep the overall species number small, equimolar amounts of TBA-OH were used so that upon redissolution in organic solvents, a monoanionic species, $\mathrm{TBA}^{+} /{ }^{-} \mathrm{HO}_{3} \mathrm{P}-\mathrm{CH}_{2}-\mathrm{NH}-\mathrm{CH}_{2}-$ $\mathrm{COOH}$, might result, possibly being accompanied by $\mathrm{TBA}^{+} /{ }^{-} \mathrm{HO}_{3} \mathrm{P}-\mathrm{CH}_{2}-\mathrm{NH}_{2}{ }^{+}-\mathrm{CH}_{2}-$ $\mathrm{COO}^{-}$in highly polar organic media. However, independent of the structural diversity of GPS, the use of $\mathrm{TBA}^{+}$as a counterion makes it possible to form a stable hydrogenbonded complex with the guanidinium receptor of $\mathbf{I}$ in organic solvents (Figure 1a). The binding of an anion to the guanidinium receptor, which is one of the two donor units in the chromophore fragment of $\mathbf{I}$, enhances the electron richness of this unit, thus reinforcing the CT character and leading to redshifts. In the following, the interaction of I with GPS-TBA was investigated via absorption and fluorescence titrations in $\mathrm{CHCl}_{3}$ and $\mathrm{MeCN}$.

Upon the addition of GPS-TBA to a dilute solution of $\mathbf{I}$ in $\mathrm{CHCl}_{3}$, a bathochromic shift was observed, accompanied by a decrease of absorption and fluorescence signals (see Figure $1 \mathrm{~b}, \mathrm{c}$ ). Additionally, a 5-nm shift was discovered in absorption with an isosbestic point at $474 \mathrm{~nm}$, while a 15-nm shift was recorded in the fluorescence emission. Upon titration of I with GPS-TBA in MeCN, a more polar solvent, smaller bathochromic shifts were observed (a 3-nm red shift in absorption and a 12-nm shift in fluorescence emission) (Figure 1d,e). An isosbestic point in the absorption spectra was observed at $483 \mathrm{~nm}$. The corresponding excitation spectra, before and after the formation of the complex between I and GPS-TBA, reveal that the fluorescence emission stems from these two species (Figure S8).

Comparison of the binding behavior in $\mathrm{CHCl}_{3}$ and $\mathrm{MeCN}$ at equimolar concentrations showed that the saturation in MeCN occurred with $<0.8$ equivalents of GPS-TBA, compared to $0.9-1$ equivalents of GPS-TBA in $\mathrm{CHCl}_{3}$ (Figure 2), indicating a more complex binding 
stoichiometry between $\mathbf{I}$ and GPS-TBA in $\mathrm{CHCl}_{3}$ and $\mathrm{MeCN}$ than a single 1:1 complex (for details on binding constant determination, see Section 9, Supplementary Material; [56]).

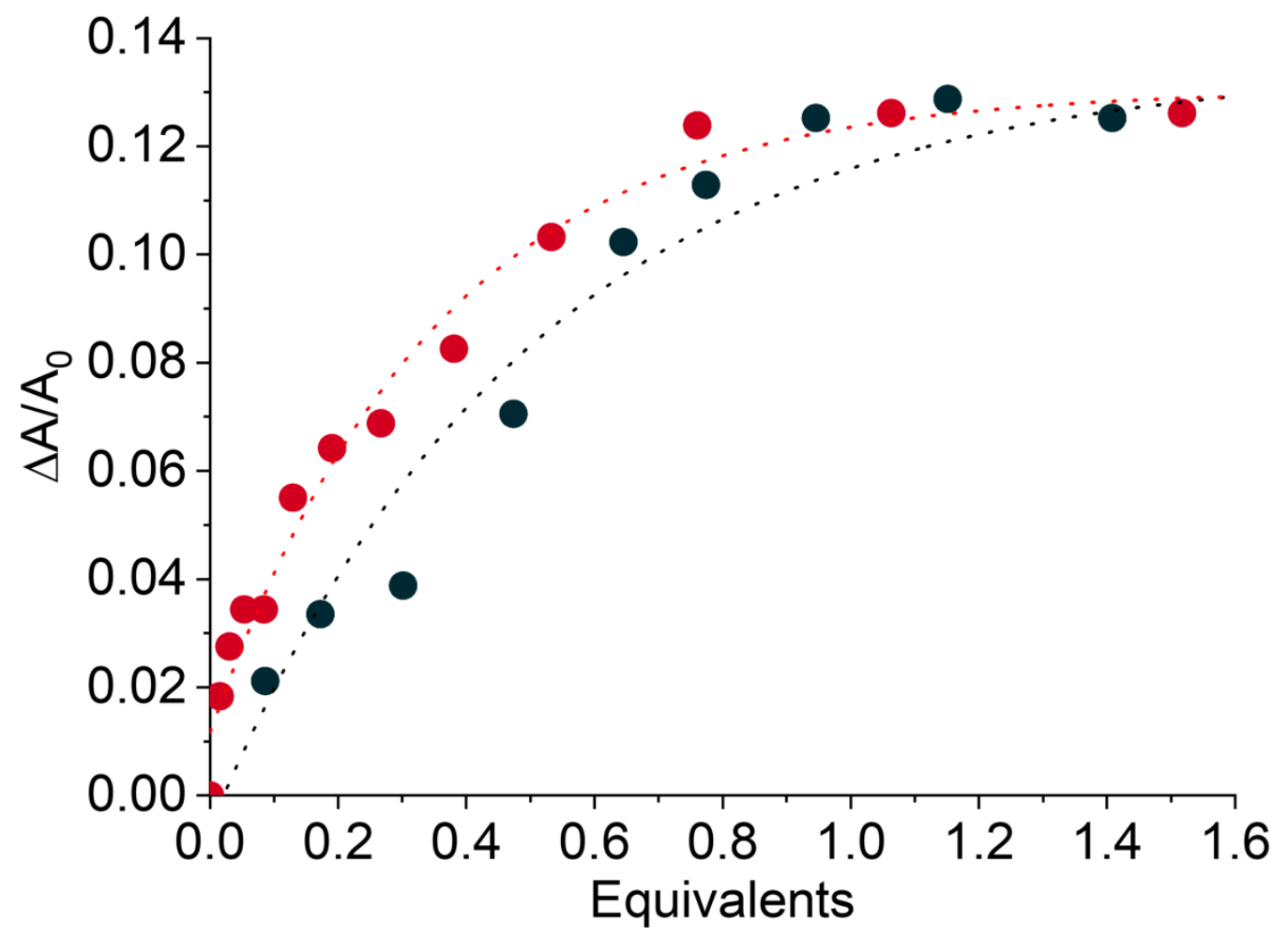

Figure 2. Comparison of relative changes in absorbance $\left(\triangle A / A_{0}\right)$ upon titration of $\mathbf{I}$ with GPS-TBA in $\mathrm{CHCl}_{3}$ (black squares) and $\mathrm{MeCN}$ (red circles). $\Delta A=\left(A_{\max }-A_{0}\right) / A_{0}$, where $A_{\max }$ is the absorbance at $446 \mathrm{~nm}\left(\mathrm{CHCl}_{3}\right)$ or $444 \mathrm{~nm}(\mathrm{MeCN})$ after each addition of GPS-TBA, while $A_{0}$ is the absorbance of I at $446 \mathrm{~nm}\left(\mathrm{CHCl}_{3}\right)$ or $444 \mathrm{~nm}(\mathrm{MeCN})$. Fits (dotted lines) are included for better illustration.

To further investigate this behavior, Job plots were constructed for GPS-TBA, with I in $\mathrm{CHCl}_{3}$ and $\mathrm{MeCN}$. The contribution of I-GPS-TBA to the changes in the absorption signal of the dye-template mixture $\left(\mathrm{Y}_{\lambda}\right)$ was plotted against the molar ratio of GPS-TBA [57]. In $\mathrm{CHCl}_{3}$, it was found that 2 moles of GPS-TBA could form a complex with 3 moles of $\mathbf{I}$ (I:GPS-TBA 1.5:1 stoichiometry, see Figure 3a and Figure S9a, Supplementary Material). Higher-order broken stoichiometries such as 3:2 are commonly not encountered at dilute concentrations for species that possess either only one or two binding sites; therefore, we tentatively assume that the apparent 1.5:1 stoichiometry is, in fact, a mixture of a 1:1 and a 2:1 stoichiometry. Because the binding behavior can be even more complex and involve different host-to-guest orientation, and orientation and stoichiometry can themselves be solvent-dependent, the data were pragmatically fitted to 1:1 or 2:1 binding models to derive information about complex stabilities that would be important for the MIP formation step [56]. For $\mathrm{CHCl}_{3}$, the titration data fitted best to a 1:1 stoichiometry, with an apparent complex stability constant: $\mathrm{K}_{\mathrm{I}-\mathrm{GPS}-\mathrm{TBA}}^{\mathrm{CHCl}_{3}}=3.5( \pm 0.5) \times 10^{7} \mathrm{M}^{-1}$. On the other hand, in MeCN, 1 mole of GPS-TBA complexed with 2 moles of I (I:GPS-TBA 2:1 stoichiometry, see Figure $3 b$ and Figure S9b, Supplementary Material). Consequently, the titration data in MeCN fit a 2:1 binding model where $\mathrm{K}_{\mathrm{I}-\mathrm{MPS}-\mathrm{TBA}}^{\mathrm{MeCN}}=6.9( \pm 1.3) \times 10^{6} \mathrm{M}^{-1}$ and $\mathrm{K}_{\mathrm{I}_{2}-\mathrm{GPS}-\mathrm{TBA}}^{\mathrm{MeCN}}=7.8( \pm 0.2) \times 10^{3} \mathrm{M}^{-1}[56,58]$. These values are comparable to the binding strengths observed for similar systems [51] and also indicate that the formation of the 2:1 complex is aggravated with respect to the 1:1 complex in MeCN. 
(a)

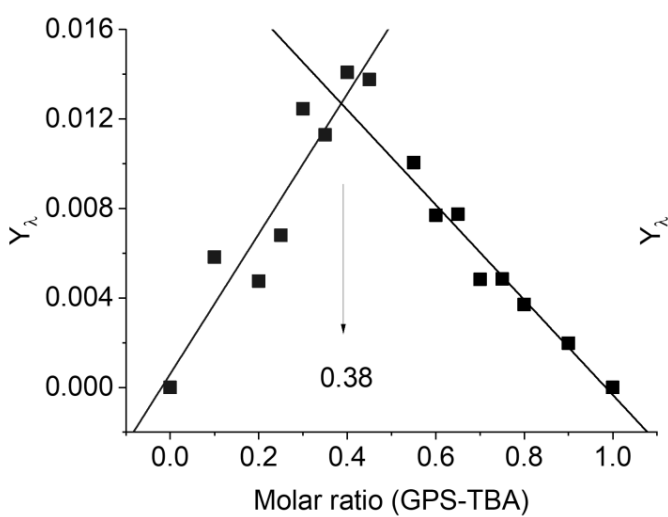

(b)

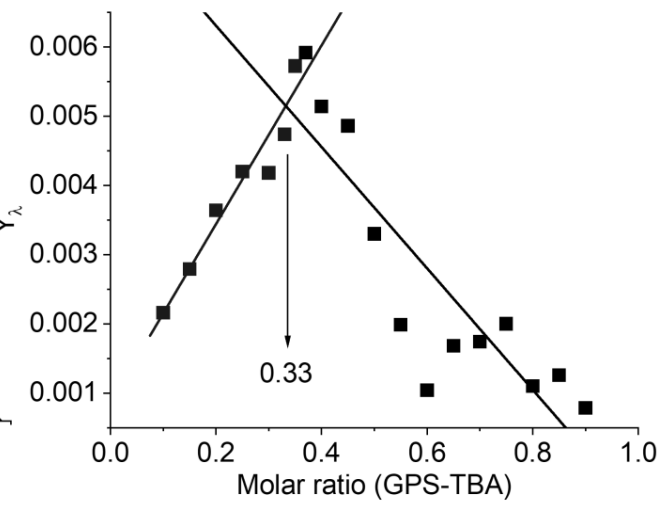

Figure 3. Job plots for the titration of I with GPS-TBA in (a) $\mathrm{CHCl}_{3}$ and (b) $\mathrm{MeCN}$, showing the contribution of I-GPS-TBA complex to the absorption signal $\left(\mathrm{Y}_{\lambda}\right)$, plotted against the molar ratio of GPS-TBA in solution.

The differences in the binding stoichiometries were attributed to the polyprotic nature of GPS-TBA. Although an equimolar amount of TBA-OH was used to facilitate the dissolution of GPS yet avoid the formation of GPS-TBA 2 , i.e., $\mathrm{TBA}^{+} /{ }^{-} \mathrm{HO}_{3} \mathrm{P}-\mathrm{CH}_{2}-\mathrm{NH}-$ $\mathrm{CH}_{2}-\mathrm{COO}^{-} / \mathrm{TBA}^{+}$, the presence of several protic groups in the molecule could still result in different species in $\mathrm{CHCl}_{3}$ and $\mathrm{MeCN}$, as described above. In aqueous media, GPS is known to form a zwitterionic species even in the net neutral state, at a strongly acidic $\mathrm{pH}$, and a dianionic species at a neutral $\mathrm{pH}$. In organic solvents, progressively destabilizing ionic species with decreasing polarity of the solvent, the formation of less charged species is favored. $\mathrm{CHCl}_{3}$ is a medium polar solvent, in which the ionic forms of GPS (Figure 1a, middle and right) would be less energetically stable. The addition of equimolar amounts of TBA-OH should, thus, preferentially result in the formation of the species shown in Figure 1a, left. However, the binding stoichiometry could be a mixture of a 1:1 and a 2:1 model when more than the species shown in Figure 1a, left, are present. Yet, Figure 4a suggests that the 1:1 model is prevalent. On the other hand, the zwitterionic form of GPS may be more stable in the polar environment provided by $\mathrm{MeCN}$ (Figure 1a, middle and right). Consequently, two anionic groups can be present to which I can bind, resulting in an I:GPS-TBA 2:1 stoichiometry (Figure 1a, left and middle; Figure 4b), though 1:1 complexation is clearly favored. NMR titration studies performed in $\mathrm{CD}_{3} \mathrm{CN}$ also revealed that the 1:1 interaction should be the dominant binding mode (Figures S10-S16, Section 11, Supplementary Material).
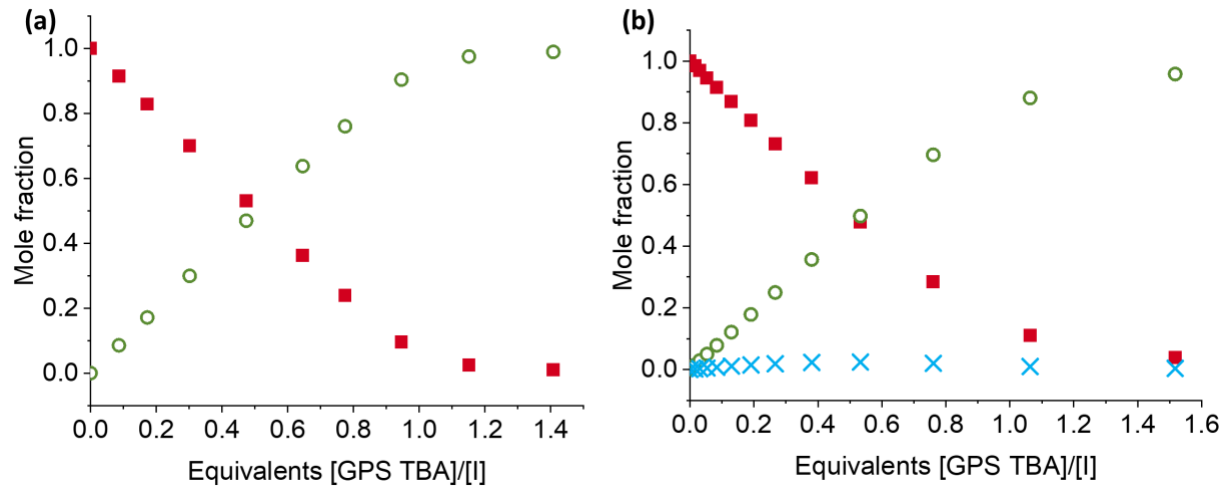

Figure 4. (a) Species distribution of [I] (red squares) and [I-GPS-TBA] (green circles) during the titration in $\mathrm{CHCl}_{3}$, with fitting to 1:1 stoichiometry using BindFit. (b) Species distribution of [I] (red squares), [I-GPS-TBA] (green circles) and [ $\mathbf{I}_{2}$-GPS-TBA] (blue crosses) during the titration in $\mathrm{MeCN}$, with fitting to I:GPS-TBA 2:1 stoichiometry using BindFit. 
Even if different complexes can (co-)exist, stoichiometric imprinting can be performed with binding constants $>10^{3} \mathrm{M}^{-1}$ to ensure the adequate complexation of the target analyte in the pre-polymerization mixture [59]. The binding constants obtained for I and GPS-TBA were satisfactory in this regard, and MIP synthesis could be performed.

\subsection{Synthesis and Characterization of Molecularly Imprinted Polymer Particles}

MIPs, synthesized as a thin layer on a substrate, allow the analyte to penetrate the matrix more easily, eventually reaching the binding sites, compared to bulk MIPs. Therefore, sub-micron silica particles were used as supports for MIP synthesis due to their ease of preparation and functionalization. The silica particles were grafted with RAFT groups to facilitate controlled polymerization on the particle surface.

The synthesis and functionalization of the silica particles were according to our previous work $[46,60]$. First, the silica particles were grafted with amino groups by a reaction with APTES, followed by the condensation of the amino groups with the carboxylic acid group of a RAFT agent, CPDB (Figure 5a). The different synthesis and functionalization steps of the silica particles led to changes in the particle surface properties, as revealed by zeta potential measurements (see Figure S17, Supplementary Material). As expected in purified water at $\mathrm{pH}$ 6, silica particles yielded a negative surface charge due to the presence of silanol groups. APTES modification introduced amino groups on the surface, leading to a net positive surface charge in APTES@SiO $\mathbf{S}_{2}$, whose magnitude was reduced after reaction with CPDB to graft RAFT groups onto the surface, yielding RAFT@SiO ${ }_{2}$. The amount of the RAFT groups was determined by the elemental analysis of sulfur $(0.2123 \%)$ to be $0.033 \mathrm{mmol} \mathrm{g}^{-1}$. Based on the specific surface area of the silica particles, determined from porosimetry $\left(20.06 \mathrm{~m}^{2} \mathrm{~g}^{-1}\right)$, the density of RAFT groups on the particle surface was determined to 1.0 RAFT groups $\mathrm{nm}^{-2}$ (see Figure S18, Supplementary Material).

(a)
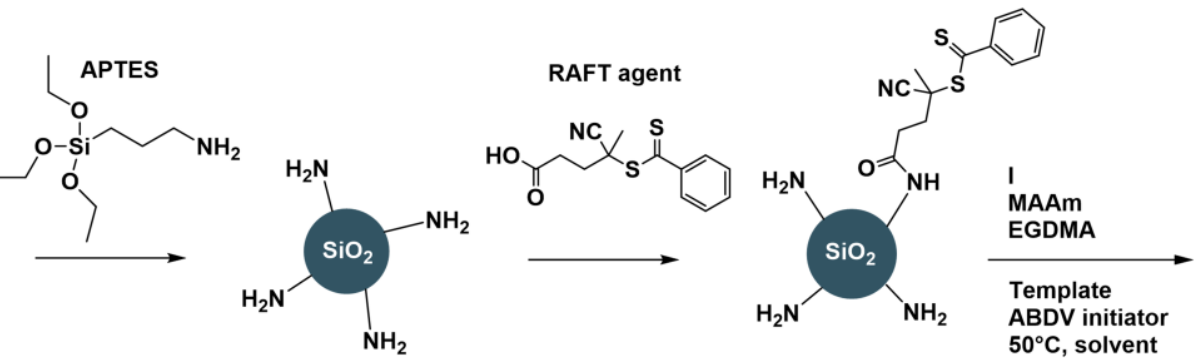

(i) $\mathrm{SiO}_{2}$

(ii) APTES@SiO

(iii) RAFT@ $\mathrm{SiO}_{2}$

(b)

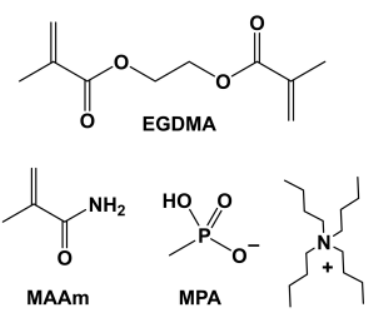

(c)

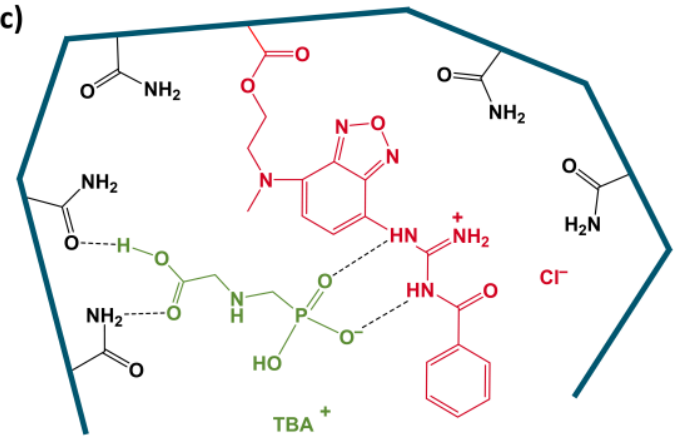

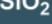

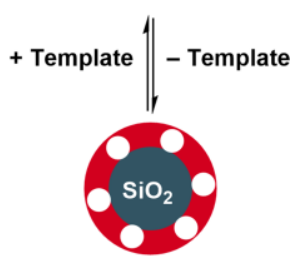

(iv) MIP/NIP@SiO

Figure 5. (a) Synthesis scheme for MIP and dNIP particles. (b) Comonomer and crosslinker used in the synthesis of MIP/dNIP particles, and the structure of MPA-TBA, used as a "dummy" template in the synthesis of dNIPs with I. (c) Incorporation of fluorescent monomer I, template and comonomer in the polymer matrix. After MIP synthesis, the template was extracted to yield binding cavities.

In addition to the probe monomers and templates, other comonomers were employed for MIP synthesis. Methacrylamide (MAAm) and ethylene glycol dimethacrylate (EGDMA) 
were chosen as the comonomer and crosslinker, respectively (Figure 5b). In previous reports we published, describing a similar system, MAAm did not affect complex formation between a fluorescent sensing monomer and the target template [60], and EGDMA is widely used in the synthesis of MIP sensors when addressing polar analytes. The combination of fluorescent monomer I, GPS template, MAAm and EGDMA was expected to lead to the formation of high-affinity cavities for the binding of GPS templates in the MIP layer (Figure 5c).

Non-imprinted polymer particles (NIPs) were concurrently synthesized to compensate for non-specific interactions. We have previously shown that conventional NIPs, prepared without a template, possess a random arrangement of functional monomers that could result in high unspecific binding, but the inclusion of a "dummy" template helps to orient the functional groups in a manner that is similar to the MIP, such that the surface characteristics of the resulting polymer shell in the "dummy" NIP (dNIP) particles resemble those of the MIPs [61]. Accordingly, methyl phosphonic acid (MPA)-TBA (Figure 5c) was employed as a "dummy" template for the synthesis of "dummy" NIPs (dNIPs) with I, since the MPA anion, which contains the phosphonic acid group and is a known metabolite of GPS, was expected to interact with I in a comparable manner, i.e., through stoichiometric 1:1 complex formation (Figure S19, Supplementary Material).

Compared to titrations in dilute solution, higher concentrations of the probe are used in the polymerization reaction. The stability of the probe-template complexes in the presence of other polymerization components used in polymer synthesis was crucial to ensure the formation of high-affinity binding sites in the MIPs. Consequently, the UV/vis absorption and fluorescence spectra of the pre-polymerization mixtures were recorded in the presence and absence of the template, to determine if the bathochromic shifts observed in the dilute solution after analyte addition were retained at higher concentrations in the presence of MAAm and EGDMA.

To achieve the strongest possible responses in a MIP, a stoichiometry of I:GPS-TBA (or MPA-TBA) was chosen that allows for maximal spectroscopic changes in the prepolymerization mixtures involving $\mathrm{MeCN}$ or $\mathrm{CHCl}_{3}$, as well as MAAm and EGDMA, ensuring the formation of high-affinity binding sites (see Figures S20 and S21, Supplementary Material, Table 1). Because the concentration range used for polymerization and the components in the system differ significantly from those of the host-guest model studies described above, this practical approach is more suitable for MIP synthesis. Moreover, for optically responding MIPs, it is also beneficial when all the fluorescent probe monomers are engaged in complexation in a defined way upon starting the polymerization, and when the single fluorophore units are well separated in the polymer matrix, avoiding fluorophore crosstalk. In this regard, the employment of equimolar amounts of I and GPS-TBA yielded the best results under pre-polymerization conditions. MIP and dNIP particles were therefore synthesized, applying 1:1 stoichiometry of I and GPS-TBA. The resulting particles were washed excessively with $\mathrm{MeCN}$ to remove the template. $\mathbf{M I P a} @ \mathbf{S i O}_{2}$ and $\mathbf{d N I P a} @ \mathrm{SiO}_{2}$, i.e., MIP or dNIP shells on silica core particles, were synthesized in $\mathrm{CHCl}_{3}$, and $\mathbf{M I P b} @ \mathrm{SiO}_{2}$ and $\mathbf{d N I P b} @ \mathrm{SiO}_{2}$ in $\mathrm{MeCN}$.

The synthesized core-shell MIP and dNIP particles were characterized by thermogravimetric analysis (TGA) and transmission electron microscopy (TEM). The TGA measurements showed changes in the mass loss upon the combustion of organic groups in all particles (Figure 6a). Particles prepared in $\mathbf{M e C N}\left(\mathbf{M I P b} @ \mathbf{S i O}_{2}\right.$ and $\left.\mathbf{d N I P b} @ \mathbf{S i O}_{2}\right)$ displayed higher mass loss compared to particles prepared in $\mathrm{CHCl}_{3}\left(\mathbf{M I P a} @ \mathbf{S i O}_{\mathbf{2}}\right.$ and $\left.\mathbf{d N I P a} @ \mathbf{S i O}_{2}\right)$. Apparently, the larger mass loss from the RAFT@SiO $\mathbf{S}_{2}$, occurring at $150-220{ }^{\circ} \mathrm{C}$, was due to the presence of adsorbed organic matter on the surface of the functionalized particles that were dislodged after MIP synthesis, as we also previously reported [60]. From TEM measurements, the diameter of the core silica particles was determined to be $272 \pm 22 \mathrm{~nm}$ (Figure $6 \mathrm{~b}(\mathrm{i})$ ). The polymer shell thickness for the different particles varied significantly for the MIP and dNIP particles, depending on the porogen used (Figure 6b(iv-vii)). 
Table 1. Bathochromic shifts in absorption maxima $\left(\lambda_{\Delta}^{\mathrm{abs}}\right)$ after the addition of the templates in dilute solution and the pre-polymerization mixtures for $\mathbf{M I P a} @ \mathrm{SiO}_{2}, \mathrm{dNIPa} @ \mathrm{SiO}_{2},{\mathrm{MIPb} @ S i \mathrm{~S}_{2}}$ and $\mathbf{d N I P b} @ \mathrm{SiO}_{2}$ in the corresponding solvents. Equimolar amounts of $\mathbf{I}$ and the template were used.

\begin{tabular}{|c|c|c|}
\hline Sample & Dilute Solution, $\lambda_{\Delta}^{\text {abs }}(\mathrm{nm})$ & Prepolymerization Solution, $\lambda_{\Delta}^{\text {abs }}(\mathrm{nm})$ \\
\hline $\mathrm{MIPa} @ \mathrm{SiO}_{2}$ & 5.0 & 3.5 \\
\hline $\mathrm{dNIPa} @ \mathrm{SiO}_{2}$ & 5.0 & 3.5 \\
\hline $\mathrm{MIPb} @ \mathrm{SiO}_{2}$ & 3.0 & 2.0 \\
\hline $\mathrm{dNIPb} @ \mathrm{SiO}_{2}$ & 3.5 & 2.5 \\
\hline
\end{tabular}

(a)

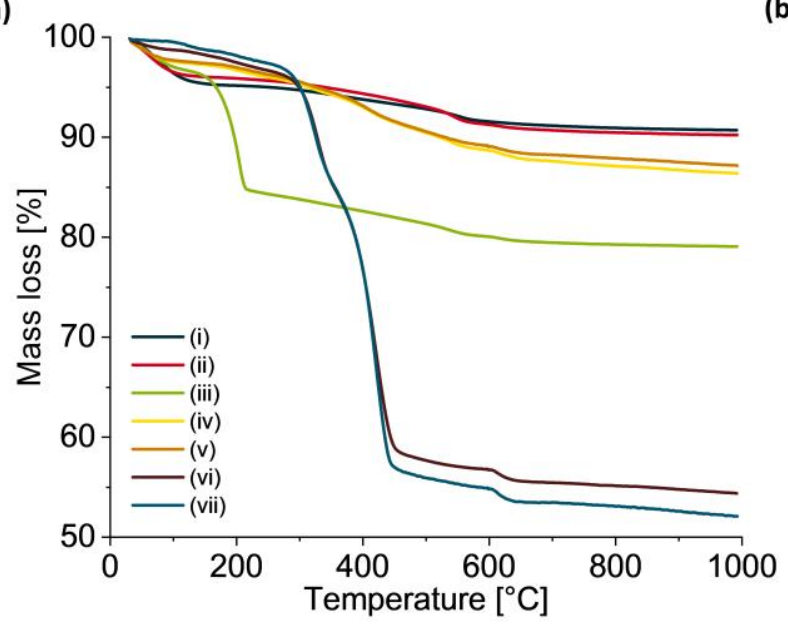

(b)

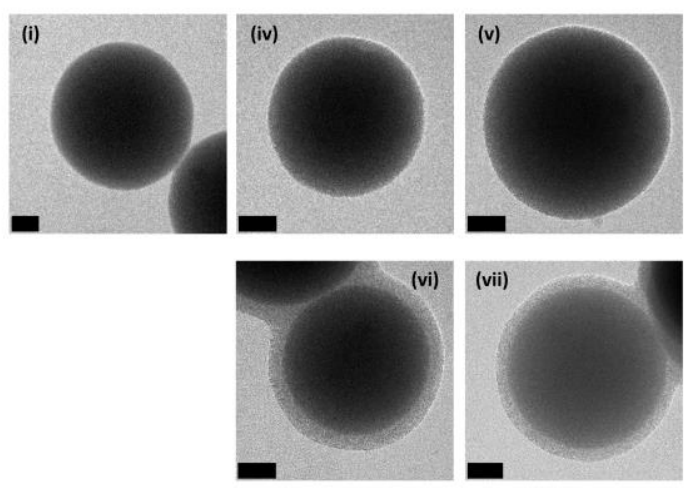

Figure 6. (a) TGA mass loss curves of (i) $\mathrm{SiO}_{2}$ particles, (ii) APTES@SiO ${ }_{2}$, (iii) $\mathrm{RAFT@SiO}{ }_{2}$, (iv) $\mathrm{MIPa} @ S i O_{2}$, (v) dNIPa@SiO ${ }_{2}$, (vi) $\mathrm{MIPb} @ S i O_{2}$ and (vii) $\mathrm{dNIPb}_{\mathrm{N}} \mathrm{SiO}_{2}$. (b) $\mathrm{TEM}$ images

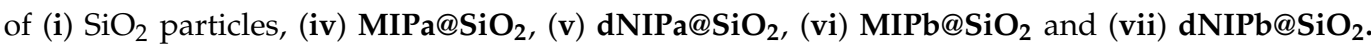
Scale bar $=50 \mathrm{~nm}$.

Table 2 summarizes the polymer shell thickness for the MIP and dNIP particles, as well as the amount of dye incorporated into the polymer shell (see Supplementary Material for further details). Particles prepared in $\mathbf{M e C N}\left(\mathbf{M I P b} @ \mathbf{S i O}_{2}\right.$ and $\left.\mathbf{d N I P b} @ \mathbf{S i O}_{2}\right)$ possessed shells thicker than $30 \mathrm{~nm}$, while in $\mathrm{CHCl}_{3}\left(\mathbf{M I P a} @ \mathbf{S i O}_{2}\right.$ and $\left.\mathbf{d N I P a} @ S i \mathbf{S}_{2}\right), 2-3 \mathrm{~nm}$ polymer shells were obtained, which is in good agreement with the higher mass loss obtained from TGA measurements in the case of $\mathbf{M I P b} @ S i_{2}$ and $\mathbf{d N I P b} @ S_{i O}$ (Figure 6a).

Table 2. Polymer shell thickness and amount of incorporated dye for the synthesized MIP and dNIP particles.

\begin{tabular}{|c|c|c|}
\hline Sample & Polymer Shell Thickness (nm) & Incorporated Dye ( $\mu \mathrm{mol} \mathrm{g}^{-1}$ of Particles) \\
\hline $\mathrm{MIPa} @ \mathrm{SiO}_{2}$ & $2.7 \pm 1.3$ & $1.16 \pm 0.03$ \\
\hline $\mathrm{dNIPa} @ \mathrm{SiO}_{2}$ & $2.3 \pm 0.9$ & $1.17 \pm 0.03$ \\
\hline $\mathrm{MIPb} @ \mathrm{SiO}_{2}$ & $36.6 \pm 10.3$ & $6.33 \pm 0.04$ \\
\hline $\mathrm{dNIPb} @ \mathrm{SiO}_{2}$ & $38.1 \pm 17.4$ & $6.14 \pm 0.30$ \\
\hline
\end{tabular}

Although the recipe used for the preparation of MIPs with I in both solvents was identical, the particles prepared in MeCN had polymer shells that were 15-fold thicker than those prepared in $\mathrm{CHCl}_{3}$, and the amount of dye incorporated into the $\mathrm{MeCN}$-prepared particles was 6-fold larger. This indicates differences in the polymerization behavior of the system components in the two solvents. $\mathrm{CHCl}_{3}$ has been reported as a solvent to which the chain transfer of growing polymer chains can occur [62], which could result 
in the formation of polymer in solution rather than on the particle surface, such that polymer is lost during the washing steps [63]. Such processes are not expected to occur in $\mathrm{MeCN}$, and this may explain the thinner polymer shells obtained when $\mathrm{CHCl}_{3}$ was used as the porogen.

\subsection{Comparison of Fluorescence Sensing Performance of MIP Particles in $\mathrm{CHCl}_{3}$ and $\mathrm{MeCN}$}

Due to the incorporation of fluorescent probes into the polymer matrix, the selectivity of the MIP and dNIP particles could be directly evaluated through fluorescence titrations of the particles with the corresponding analytes. The particles were suspended in the corresponding solvents $\left(\mathrm{CHCl}_{3}\right.$ or $\left.\mathrm{MeCN}\right)$ and the suspension was placed in a quartz cuvette. A solution of the template was added at increasing concentrations, and the fluorescence changes of the suspension were monitored.

The emission maximum of $\mathbf{M I P a} @ \mathbf{S i O}_{2}$, being synthesized in $\mathrm{CHCl}_{3}$, was found to be at $593 \mathrm{~nm}$, which is blue-shifted compared to the one of free $\mathbf{I}$ in solution $(622 \mathrm{~nm}$, Figure 1c). This is either due to a change in polarity of the surrounding polymer network that I had been incorporated into or to restricted motion in the crosslinked matrix. It is well known that when the solvent shell around a CT fluorophore cannot fully relax in a confined space like a polymer network, the excited state cannot be fully stabilized, resulting in blue-shifted emission spectra [64]. Upon the titration of $\mathbf{M I P a} @ \mathbf{S i O}_{2}$ against GPS-TBA in $\mathrm{CHCl}_{3}$, a quenching of the fluorescence response was obtained, alongside a bathochromic shift in emission (Figure 7a). The binding of $\mathbf{M I P a}_{\mathbf{S}} \mathrm{SiO}_{2}$ with GPS-TBA fit a 1:1 stoichiometry, as observed in dilute solution, with an apparent association constant of $3.95( \pm 0.49) \times 10^{4} \mathrm{M}^{-1}$. The binding strength of the MIPs was significantly lower than that of I with GPS-TBA in solution, which is possibly due to the different ionic state of GPS in the network than in bulk $\mathrm{CHCl}_{3}$. However, even though GPS and MPA are both among the dimensionally smallest components of the system and do not differ largely in

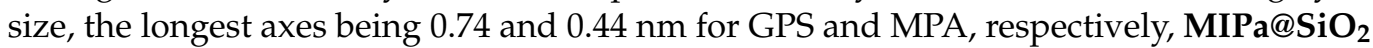
bound GPS-TBA more selectively compared to $\mathbf{d N I P a} @ S_{\mathbf{S i O}}$ (Figure 7b), with an imprinting factor (IF) of 1.9 being obtained at the saturation point of the titration (Figure 7c). Moreover, $\mathbf{M I P a} @ \mathrm{SiO}_{2}$ could also discriminate efficiently against 2,4-D-TBA and dicambaTBA, with discrimination factors (DF) of 2.1 for both pesticides, respectively (Figure 7d and Figure S22, Supplementary Material). The analytical figures of merit of $\mathbf{M I P a} @ \mathbf{S i O}_{2}$ for the sensing of GPS-TBA in $\mathrm{CHCl}_{3}$ (limit of blank, LOB and limit of detection, LOD) were calculated to be 3.2 and $4.8 \mu \mathrm{M}$, respectively, with a linear range of 7.9-40.8 $\mu \mathrm{M}$ (see Supplementary Material for further details; [65-67]). 
(a)

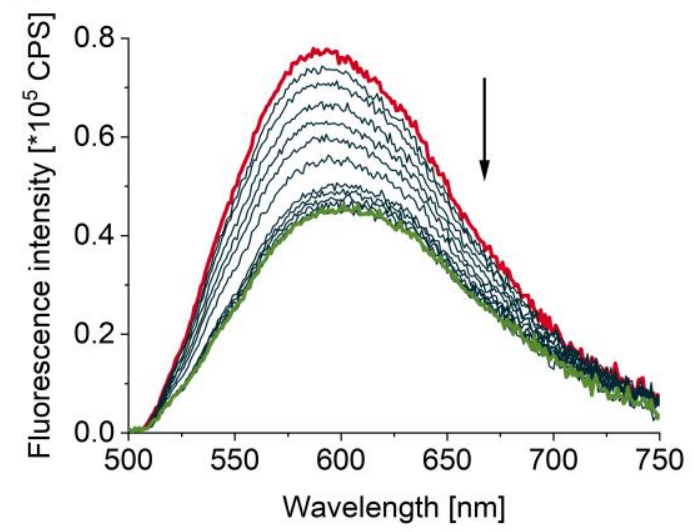

(c)

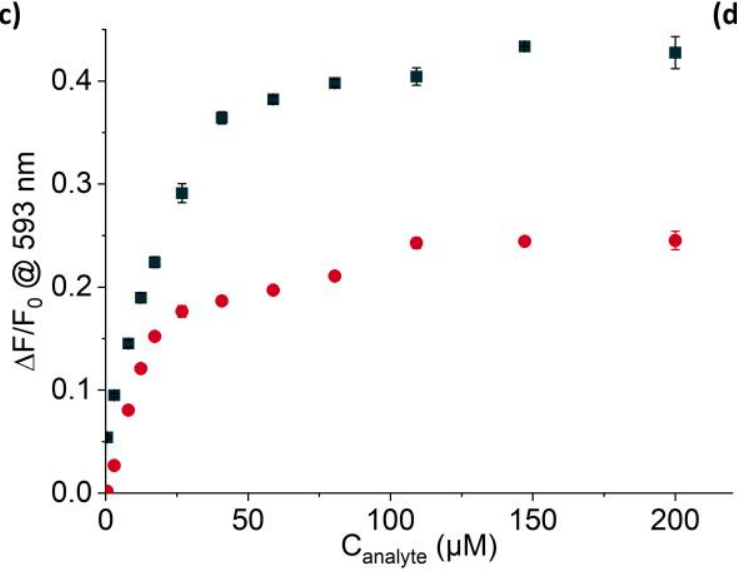

(b)

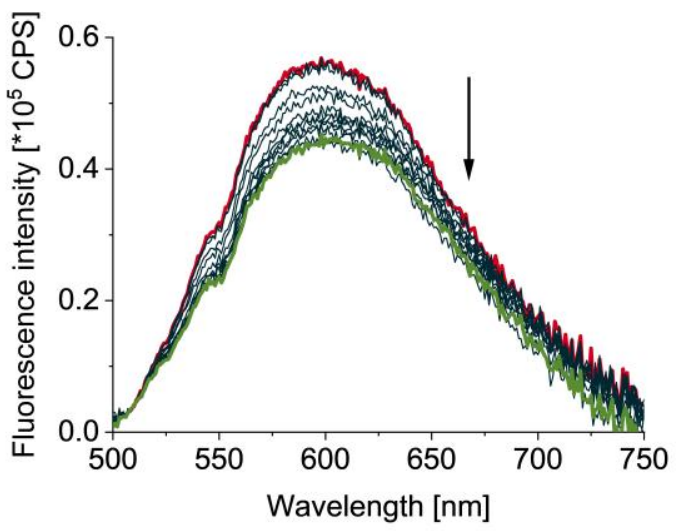

d)

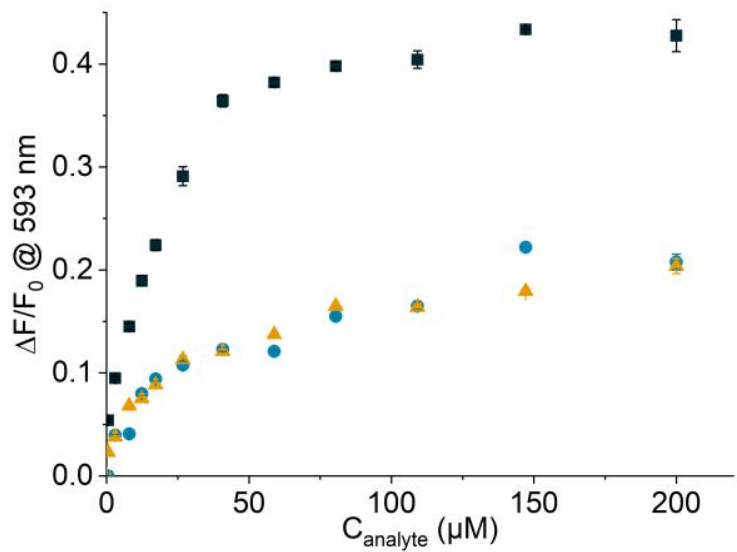

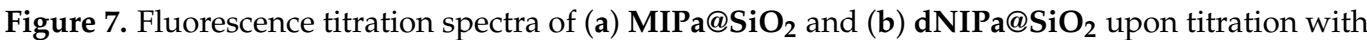
up to $200 \mu \mathrm{M}$ GPS-TBA in $\mathrm{CHCl}_{3}$. (c) Relative fluorescence changes, $\frac{\Delta F}{F_{0}}$, at $593 \mathrm{~nm}$ of $\mathbf{M I P a} @ \mathrm{SiO}_{2}$ (black squares) and $\mathbf{d N I P a} @ \mathbf{S i O}_{2}$ (red circles) upon titration with up to $200 \mu \mathrm{M}$ GPS-TBA in $\mathrm{CHCl}_{3}$. (d) Relative fluorescence changes, $\frac{\Delta F}{F_{0}}$, at $593 \mathrm{~nm}$ of $\mathbf{M I P a} @ \mathbf{S i O}_{2}$ upon titration with up to $200 \mu \mathrm{M}$ GPS-TBA (black squares), 2,4-D-TBA (blue circles) and dicamba-TBA (orange triangles) in $\mathrm{CHCl}_{3}$. $\lambda_{\text {ex }}=474 \mathrm{~nm}$. Here, $2 \mathrm{~mL}$ of $1 \mathrm{mg} \mathrm{mL}^{-1}$ particle suspensions in $\mathrm{CHCl}_{3}$ were used for the titrations.

When recording the fluorescence spectrum of $\mathbf{M I P b} @ \mathrm{SiO}_{2}$ synthesized in $\mathrm{MeCN}$, in this solvent, the emission maximum was found to be at $607 \mathrm{~nm}$, which is again blueshifted compared to the one of free $\mathbf{I}$ in solution (652 nm, Figure 1e). Comparing the magnitude of the hypsochromic shift in $\mathrm{MeCN}$ vs. $\mathrm{CHCl}_{3}$, i.e., $45 \mathrm{~nm}$ vs. $29 \mathrm{~nm}$, the confinement effects seem to be predominant as they would have a stronger effect in the more polar solvent. However, when comparing the emission maxima obtained for MIPa@SiO 2 and $\mathbf{M I P b} @ \mathbf{S i O}_{2}$, there is still a redshift observed when changing from a less polar (593 $\mathrm{nm}$ in $\mathrm{CHCl}_{3}$ ) to a more polar (607 $\mathrm{nm}$ in $\mathrm{MeCN}$ ) solvent as has also been observed in the diluted state. During the titration of $\mathbf{M I P b} @ \mathbf{S i O}_{2}$ against GPSTBA in MeCN, a fluorescence quenching and a slight bathochromic shift were also observed (Figure 8a). The data fit to a 1:1 binding model, with a binding constant of $2.01( \pm 0.16) \times 10^{4} \mathrm{M}^{-1}$. This is in agreement with the species distribution diagram (Figure $4 \mathrm{~b}$ ), in which the 2:1 complex [ $\mathbf{I}_{2}$-GPS-TBA] is present only in low amounts throughout the entire concentration range measured. Titration of $\mathbf{d N I P b} @ \mathbf{S i O}_{2}$ against GPS-TBA in $\mathrm{MeCN}$ also led to fluorescence quenching and bathochromic shifts (Figure 8b). Compared to $\mathbf{d N I P b} @ S \mathrm{O}_{2}, \mathbf{M I P b} @ \mathrm{SiO}_{2}$ showed a stronger affinity for GPS-TBA, with an IF of 1.9 being obtained (Figure 8c). The cross-selectivity of $\mathbf{M I P b} @ \mathbf{S i O}_{2}$ was evaluated against 2,4-D-TBA and dicamba-TBA, yielding DFs of 1.3 and 1.8, respectively (Figure 8d and Figure S23, Supplementary Material). In contrast to MIPs prepared in $\mathrm{CHCl}_{3}$, a lower LOB

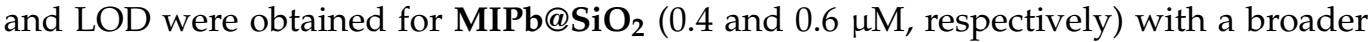


dynamic range $(7.4-200 \mu \mathrm{M})$, the latter being tentatively attributed to the thicker MIP shell formed in MeCN (Figure S24, Supplementary Material). The response kinetics in both solvents are favorably fast (Figure S25, Supplementary Material).

(a)

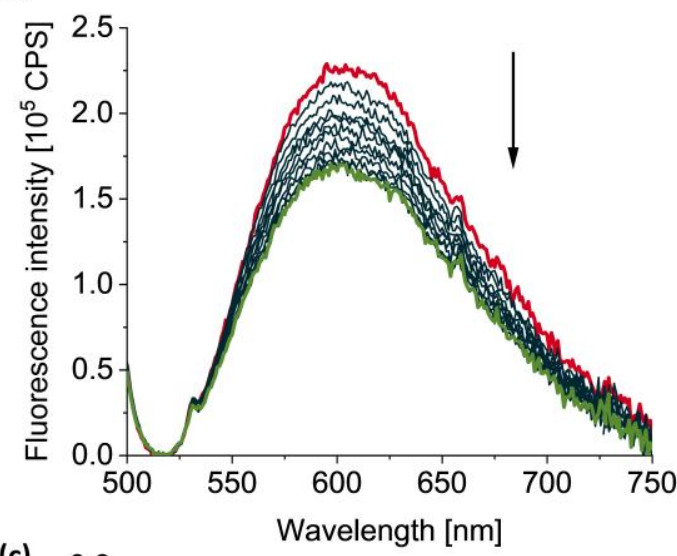

(c)

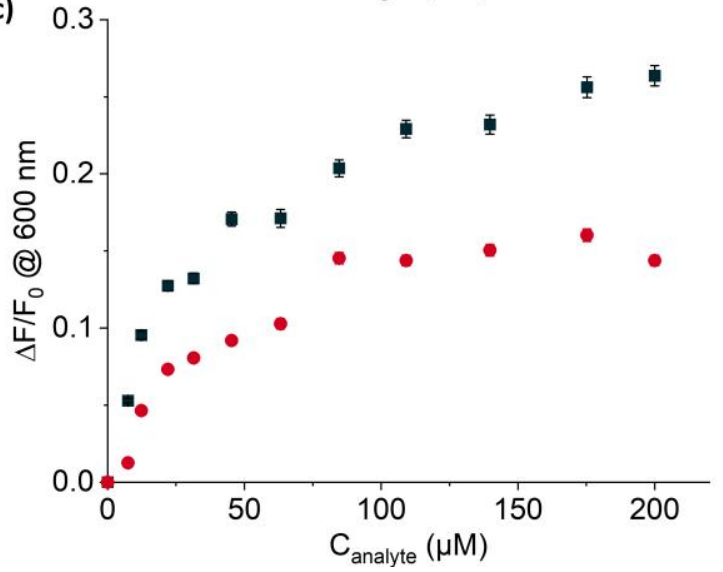

(b)

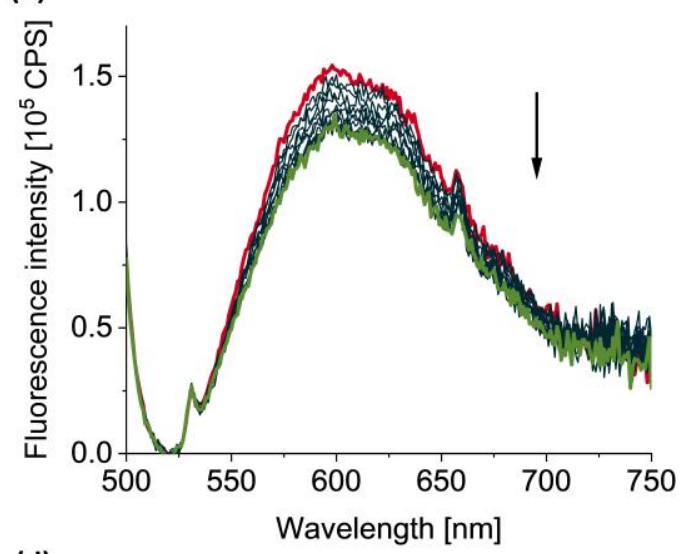

(d)

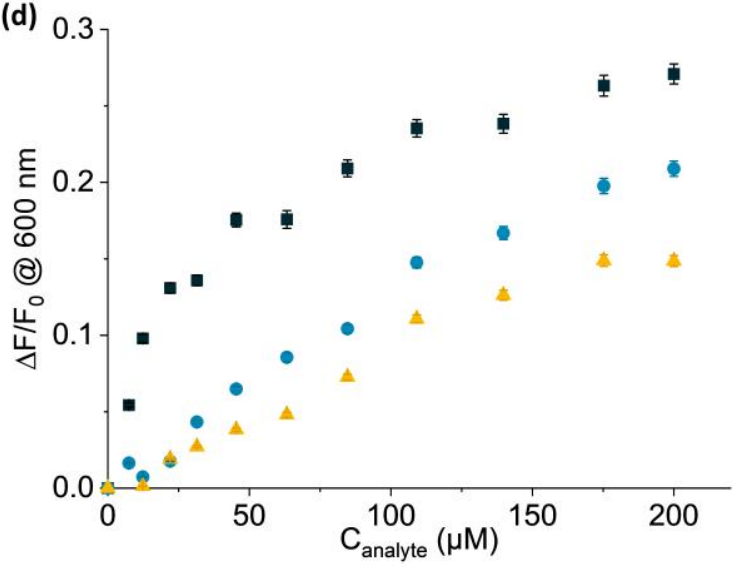

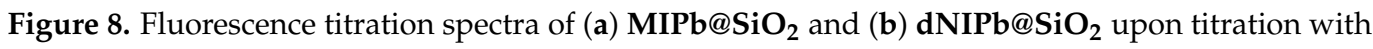
up to $200 \mu \mathrm{M}$ GPS-TBA in MeCN. (c) Relative fluorescence changes, $\frac{\Delta F}{F_{0}}$, at $600 \mathrm{~nm}$ of $\mathbf{M I P b}_{\mathbf{S i O}}$ (black squares) and $\mathbf{d N I P b @ S i O} \mathbf{S}_{2}$ (red circles) upon titration with up to $200 \mu \mathrm{M}$ GPS-TBA in MeCN.

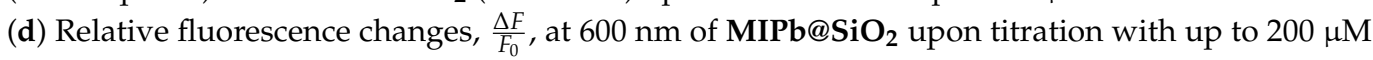
GPS-TBA (black squares), 2,4-D-TBA (blue circles) and dicamba-TBA (orange triangles) in MeCN. $\Lambda_{\mathrm{ex}}=483 \mathrm{~nm}$. Here, $2 \mathrm{~mL}$ of $1 \mathrm{mg} \mathrm{mL}^{-1}$ particle suspensions in MeCN were used in the titrations.

\section{Discussion}

The fluorescent probe monomer I bound strongly to GPS-TBA in $\mathrm{CHCl}_{3}$ and $\mathrm{MeCN}$ via a hydrogen bonding mechanism, with binding constants in the $10^{6}-10^{7} \mathrm{M}^{-1}$ range. Bathochromic shifts and decreases in absorption and fluorescence signals were observed following titrations of I with increasing amounts of GPS-TBA in both solvents in dilute solution, which were retained upon titration of $\mathbf{M I P a} @ \mathrm{SiO}_{2}$ and $\mathbf{M I P b} @ \mathrm{SiO}_{2}$ with GPSTBA. Consequently, a calibration curve could be constructed for MIPs prepared in both solvents for the sensing of GPS-TBA, and the binding constants of the MIPs to the analyte could be determined. However, with respect to discrimination against other herbicides as a crucial capability when approaching real-world applications to detect GPS in aqueous media, the MIP particles that were prepared and titrated in $\mathrm{CHCl}_{3}\left(\mathbf{M I P a} @ \mathrm{SiO}_{2}\right)$ performed better. The achieved LOD of $4.8 \mu \mathrm{M}$ makes the developed MIPs a promising material by which to detect the acceptable daily intake (ADI) of GPS in water of $0.9 \mathrm{mg} \mathrm{L}^{-1}$ $(5.32 \mu \mathrm{M})$, according to WHO guidelines [68]. These results are promising compared with the much higher values found for an anthracene-based supramolecular probe [30], and suggest that this approach can present an interesting, direct-sensing alternative, compared 
with the single-use displacement or competitive assay approaches mentioned above. MIPs operating via argon-ion laser-excited $\mathrm{Eu}^{3+}$ luminescence show comparable LODs [31].

In order to apply the materials for the detection of GPS in water, for instance, the implementation of a phase-transfer step to allow the template diffusion from an aqueous sample medium into $\mathrm{CHCl}_{3}$, where sensing can be performed, can be developed. We have recently demonstrated that fluorescent MIP particles, prepared in $\mathrm{CHCl}_{3}$, can be applied in such biphasic assays to determine analyte concentrations in water, including real-world samples [47,60,61]. Another more elegant yet also more challenging alternative would be the further advancement of the fluorescent MIP platform itself so that direct operation in aqueous mixtures becomes possible.

\section{Conclusions}

In conclusion, the synthesis of a red-emitting guanidinium benzoxadiazole donoracceptor-donor fluorescent probe monomer I was reported. Dye I exhibited emission maxima in the red spectral range and sizeable Stokes shifts of $208 \mathrm{~nm}$ and $176 \mathrm{~nm}$ in MeCN and $\mathrm{CHCl}_{3}$, respectively. Such sizeable Stokes shifts are desirable as they allow for increased signal-to-noise ratios and avoid self-quenching. The ability to show spectral shifts in absorption and fluorescence upon the binding of oxoanions at the guanidinium moiety has been successfully established. The interaction between I with GPS as TBA salt, being a herbicide of high concern due to its toxicological and ecotoxicological effects, was evaluated by UV/vis absorption and fluorescence spectroscopy. Upon addition of GPS-TBA, a bathochromic shift accompanied by a decrease of absorption and fluorescence signals was observed in $\mathrm{MeCN}$ and $\mathrm{CHCl}_{3}$. Finally, the selective recognition of GPS-TBA in $\mathrm{MeCN}$ and $\mathrm{CHCl}_{3}$ in the $\mu \mathrm{M}$ concentration range was achieved by the synthesis of fluorescent molecularly imprinted polymers (MIPs) on silica core particles. Acceptable discrimination against other herbicides, such as 2,4-D and dicamba, was achieved, being somewhat better in $\mathrm{CHCl}_{3}$ than in MeCN. In particular, the LOD of $0.6 \mu \mathrm{M}$ and the rather broad dynamic range found in $\mathrm{MeCN}$ suggest that the present approach is promising for the development of a final assay to detect GPS with sufficient reliability and confidence, in a relevant concentration range around the ADI of GPS in water, according to WHO guidelines, of $0.9 \mathrm{mg} \mathrm{L}^{-1}(5.32 \mu \mathrm{M})$ [68]. Current research in our group is devoted to device integration and further improvement of the MIP platform.

\section{Patents}

A patent on the content of this work has been filed ca. 1 year ago, the bibliographic details of which will be included once it has been published.

Supplementary Materials: The following are available online at https:/ /www.mdpi.com/article/ 10.3390/chemosensors10030099/s1, Figure S1: 1H-NMR (400 MHz, CDCl3) spectrum of 2-((7(3-benzoylguanidino)benzo[c][1,2,5]oxadiazol-4-yl)(methyl)amino)ethyl methacrylate, Figure S2: 13C-NMR (100 MHz, CDCl3) spectrum of 2-((7-(3-benzoylguanidino)benzo[c][1,2,5]oxadiazol-4yl)(methyl)amino)ethyl methacrylate, Figure S3: 1H-NMR (400 MHz, CDCl3) spectrum of compound I, Figure S4: 13C-NMR (100 MHz, CDCl3) spectrum of compound I, Figure S5: HRMS spectrum of 2-((7-(3-benzoylguanidino)benzo[c][1,2,5]oxadiazol-4-yl)(methyl)amino)ethyl methacry-late. The molecular peak corresponds to the base peak at $\mathrm{m} / \mathrm{z}=423.1843$, Figure S6: HRMS spectrum of compound I. The molecular peak is at $\mathrm{m} / \mathrm{z}=457.1371$, Figure S7: Normalized absorption and fluorescence emission spectra $(\lambda \mathrm{ex}=445 \mathrm{~nm})$ of compound $\mathrm{I}(\mathrm{c}[\mathrm{I}]=1 \times 10-5 \mathrm{M})$ in $\mathrm{MeCN}$ and $\mathrm{CHCl} 3$. The black and the red curves are the absorption and the emission in $\mathrm{MeCN}$, respectively; while the green and the blue curves are the absorption and the emission in $\mathrm{CHCl} 3$, respectively, Figure S8: (a) Excitation spectra of $\mathrm{I}(6.5 \mu \mathrm{M}, \lambda \mathrm{em}=622 \mathrm{~nm}$, red line $)$ upon addition of 1.4 equivalents of GPS-TBA $(9.2 \mu \mathrm{M}$, $\lambda \mathrm{em}=650 \mathrm{~nm}$, green line $)$ in $\mathrm{CHCl} 3$. (b) Excitation spectra of $\mathrm{I}(6.5 \mu \mathrm{M}, \lambda \mathrm{em}=652 \mathrm{~nm}$, red line $)$ upon addition of 1.5 equivalents of GPS-TBA $(9.9 \mu \mathrm{M}, \lambda \mathrm{em}=680 \mathrm{~nm}$, green line $)$ in MeCN, Figure S9: (a) $\mathrm{Y} \lambda$ for the different molar ratios for I and GPS-TBA in $\mathrm{CHCl}$. Red line represents $90 \%$ of I, blue line $60 \%$ of I and green line $10 \%$ of I. The binding is consistent with 1.5:1 (L:M) stoichiometry (b) $\mathrm{Y} \lambda$ for the different molar ratios for I and GPS TBA in MeCN. The red line represents $90 \%$ of 
I, the blue line represents $63 \%$ of I and the green line, $10 \%$ of I. The binding is consistent with 2:1 (L:M) stoichiometry, Figure S10: Numbering of the assignable protons of GPS-TBA for NMR analysis and their predicted chemical shifts (realized with ChemDraw), Figure S11: 1H-NMR spectrum of GPS-TBA in CD3CN prepared in an equimolar amount. The ratio of GPS to TBA is calculated 1.0 to 1.0. 1H-NMR $(500 \mathrm{MHz}, \mathrm{CD} 3 \mathrm{CN}): \delta(\mathrm{ppm})=3.29(\mathrm{~s}, 2 \mathrm{H}), 3.09(\mathrm{~m}, 8 \mathrm{H}), 2.85(\mathrm{~d}, 2 \mathrm{H}), 1.60(\mathrm{~m}, 8 \mathrm{H})$, 1.36 (sext, 8H), $0.97(\mathrm{t}, 12 \mathrm{H})$, Figure S12: 1H-NMR (500 MHz, CD3CN) spectrum of compound I, Figure S13: $1 \mathrm{H}$ NMR (500 MHz, CD3CN) titration spectra of I with GPS-TBA. The equivalents of GPS-TBA that are present in the different steps are (from bottom to top): $0.00,0.33,0.60,0.78,0.96$, $1.30,1.52,1.70$. The equivalents are experimentally calculated by the relation of the integral of the proton signal HC of GPS-TBA to the integral of the pro-ton signal H5 of compound I (Figures S11 and S12). The concentration of the dye is constant along the titration $\left(\mathrm{cI}=5 \times 10^{-3} \mathrm{M}\right)$, Figure S14: Magnification of the aromatic region of the $1 \mathrm{H}$ NMR $(500 \mathrm{MHz}, \mathrm{CD} 3 \mathrm{CN})$ titration spectra of I with GPS-TBA shown in Figure S13. The equivalents of GPS-TBA present in the different steps are (from bottom to top): $0.00,0.33,0.60,0.78,0.96,1.30,1.52,1.70 ; \mathrm{cI}=5 \times 10^{-3} \mathrm{M}$. Inverted commas denote the proton signals of complexed com-pound I, Figure S15: $1 \mathrm{H}$ NMR (500 MHz, CD3CN) titration spectra of GPS-TBA with I. The equivalents of compound I present in the different steps are (from bottom to top): $0.00,0.20,0.37,0.53,0.70$ and 0.90 . The equivalents are experimentally calculated by the relation of the integral of the proton signal $\mathrm{H} 5$ of compound I to the integral of the proton signal HC of GPS-TBA (Figures S11 and S12). The concentration of GPS-TBA is constant along the titration $\left(\mathrm{cGPS}-\mathrm{TBA}=5 \times 10^{-3} \mathrm{M}\right)$, Figure S16: Magnification of the GPS region of the $1 \mathrm{H} \mathrm{NMR}(500 \mathrm{MHz}$, $\mathrm{CD} 3 \mathrm{CN}$ ) titration spectra of GPS-TBA with I. The equivalents of compound I present in the different steps are (from bottom to top): 0.00, 0.20, 0.37, 0.53, 0.70 and 0.90; cGPS-TBA $=5 \times 10^{-3} \mathrm{M}$, Figure S17: Zeta potential measured at pH 6 of (i) SiO2 particles, (ii) APTES@SiO2, (iii) RAFT@SiO2, Figure S18: (a) Volume of nitrogen adsorbed per gram of $\mathrm{SiO} 2$ and (b) BET surface area plot, Figure S19: (a) Absorption and $(b)$ fluorescence spectra $(\lambda e x=474 \mathrm{~nm})$ for titration of I $(10.8 \mu \mathrm{M})$ with MPA-TBA $(0.4-37.2 \mu \mathrm{M})$ in $\mathrm{CHCl} 3$. Red line is spectrum of $\mathbf{I}$ in $\mathrm{CHCl}_{3}$, while the green line shows the spectrum of $\mathbf{I}$ after addition of up to 3.4 equivalents of MPA-TBA. The binding fit a 1:1 stoichiometry, with $\mathrm{K}_{\mathrm{I}-\mathrm{MPA}-\mathrm{TBA}}^{\mathrm{CHCl}_{3}} 3.18( \pm 0.03) \times 10^{5} \mathrm{M}^{-1}$. (c) Absorption and (d) fluorescence spectra $\left(\lambda_{\mathrm{ex}}=479 \mathrm{~nm}\right)$ for titration of $\mathbf{I}(10.0 \mu \mathrm{M})$ with MPA-TBA $(2.0-19.8 \mu \mathrm{M})$ in MeCN. The red line is the spectrum of $\mathbf{I}$ in $\mathrm{MeCN}$, while the green line shows the spectrum of $\mathbf{I}$ after addition of up to 2.0 equivalents of MPA-TBA. The binding fits a 1:1 stoichiometry, with $\mathrm{K}_{\mathrm{I}-\mathrm{MPA}-\mathrm{TBA}}^{\mathrm{MeCN}} 1.18( \pm 0.07) \times 10^{7} \mathrm{M}^{-} 1$, Figure S20: Absorption spectra of pre-polymerization mixtures of the different MIP and dNIP particles, using a 1:1 stoichiometry of I:GPS-TBA or I:MPA-TBA. (a) Spectra in CHCl3 of I + MAAm + EGDMA (red line), I + MAAm + EGDMA + GPS-TBA (green line) and I + MAAm + EGDMA + MPA-TBA (black line). Equimolar amounts of I and GPS-TBA and I and MPA-TBA were used. (b) Spectra in MeCN of I + MAAm + EGDMA (red line), I + MAAm + EGDMA + GPS-TBA (green line) and I + MAAm + EGDMA + MPA-TBA (black line), Figure S21: Normalized absorption spectra of pre-polymerization mixtures of the MIP and dNIP particles using a 1:1 stoichiometry of I:GPS-TBA or I:MPA-TBA. (a) Spectra in $\mathrm{CHCl} 3$ of I + MAAm + EGDMA (red line), I + MAAm + EGDMA + GPS-TBA (green line) and I + MAAm + EGDMA + MPA-TBA (black line). (b) Spectra in MeCN of I + MAAm + EGDMA (red line), I + MAAm + EGDMA + GPS-TBA (green line) and I + MAAm + EGDMA + MPA-TBA (black line), Figure S22: Fluorescence titration spectra $(\lambda \mathrm{ex}=474 \mathrm{~nm})$, following the titration of MIPa@SiO2 in $\mathrm{CHCl} 3$ with up to $200 \mu \mathrm{M}$ of (a) 2,4-D-TBA and (b) dicamba-TBA. The red line shows the spectrum of MIPa@SiO2 in $\mathrm{CHCl} 3$, while the green line shows the spectrum of MIPa@SiO2 after the addition of $200 \mu \mathrm{M}$ of the corresponding template in $\mathrm{CHCl}$, Figure S23: Fluorescence titration spectra $(\lambda \mathrm{ex}=483.5 \mathrm{~nm})$ following titration of $\mathrm{MIPb} @ S i O 2$ in $\mathrm{MeCN}$ with up to $200 \mu \mathrm{M}$ of (a) 2,4-D-TBA and (b) dicamba-TBA. The red line is spectrum of MIPb@SiO2 in MeCN, while the green line shows the spectrum of MIPb@SiO2 after the addition of $200 \mu \mathrm{M}$ of the corresponding template in MeCN, Figure S24: Logistic curve fitting using fluorescence emission intensity (a) at $593 \mathrm{~nm}$ for $\mathrm{MIPa} @ \mathrm{SiO}_{2}$ in $\mathrm{CHCl} 3(\lambda \mathrm{ex}=474 \mathrm{~nm})$ and $(\mathrm{b})$ at $600 \mathrm{~nm}$ for MIPb@SiO2 in MeCN $(\lambda e x=483.5 \mathrm{~nm})$. Here, $2 \mathrm{~mL}$ of $1 \mathrm{mg} \mathrm{mL}^{-1}$ suspensions of particles in the respective solvents were used, Figure S25: Kinetics of the interaction of $2 \mathrm{~mL}$ of $1 \mathrm{mg} \mathrm{mL}^{-1}$ (a) MIPa@SiO2 in CHCl3 and (b) MIPb@SiO2 in MeCN after addition of $130 \mu \mathrm{M}$ GPS-TBA, respectively, to the particle suspensions. The suspensions were mixed for $30 \mathrm{~s}$ for equilibration, after which the template solution was added and mixing continued. Similar results were expected for the dNIP particles, due to comparable shell thickness in the respective solvents. The signal decrease upon the addition of the template was virtually instantaneous in the case of $\mathrm{CHCl}_{3}$, while in $\mathrm{MeCN}$, it took ca. $30 \mathrm{~s}$ before equilibrium was reached. This can be explained 
by the longer diffusion times due to the thicker MIP shells that were formed when MeCN was used as a porogen during the synthesis. Kinetics were recorded at $\lambda_{\mathrm{ex}}=474 \mathrm{~nm}$ and $\lambda_{\mathrm{em}}=593 \mathrm{~nm}$ in $\mathrm{CHCl}_{3}$, and $\lambda_{\mathrm{ex}}=483 \mathrm{~nm}$ and $\lambda_{\mathrm{em}}=600 \mathrm{~nm}$ in $\mathrm{MeCN}$.

Author Contributions: Conceptualization, M.K., V.V., K.G. and K.R.; methodology, M.K., V.P.-P., V.V. and K.G.; writing - original draft preparation, M.K. and V.P.-P.; writing—review and editing, M.K., V.P.-P., V.V., K.G. and K.R.; visualization, M.K., V.P.-P. and K.G.; supervision, V.V., K.G. and K.R. All authors have read and agreed to the published version of the manuscript.

Funding: This work has received funding from the European Union's Horizon 2020 research and innovation program under the Marie Skłodowska-Curie Action (MSCA) grant agreement No 721297 (GlycoImaging) and the Research and Innovation Action (RIA) grant agreement No 848098 (REVERT)

Institutional Review Board Statement: Not applicable.

Informed Consent Statement: Not applicable.

Data Availability Statement: The data that support the findings of this study are available from the corresponding author upon reasonable request.

Acknowledgments: We thank S. R. Pokhrel and J. Olbeter (BAM) for their support with the synthesis of the fluorescent molecular probe, K. Meyer (BAM) for NMR measurements, J. Lisec (BAM) for high-resolution MS measurements, K. Keil (BAM) for synthesis and characterization of silica beads, A. Meckelburg (BAM) for elemental analysis, M. Grüneberg (BAM) for TGA and A. Zimathies (BAM) for measurements of the BET surface area.

Conflicts of Interest: The authors declare no conflict of interest.

\section{References}

1. Duke, S.O.; Powles, S.B. Glyphosate: A once-in-a-century herbicide. Pest Manag. Sci. 2008, 64, 319-325. [CrossRef] [PubMed]

2. Hébert, M.-P.; Fugère, V.; Gonzalez, A. The overlooked impact of rising glyphosate use on phosphorus loading in agricultural watersheds. Front. Ecol. Environ. 2019, 17, 48-56. [CrossRef]

3. Benbrook, C.M. Trends in glyphosate herbicide use in the United States and globally. Environ. Sci. Eur. 2016, 28, 3. [CrossRef] [PubMed]

4. Tarazona, J.V.; Court-Marques, D.; Tiramani, M.; Reich, H.; Pfeil, R.; Istace, F.; Crivellente, F. Glyphosate toxicity and carcinogenicity: A review of the scientific basis of the European Union assessment and its differences with IARC. Arch. Toxicol. 2017, 91, 2723-2743. [CrossRef] [PubMed]

5. Motta, E.V.S.; Raymann, K.; Moran, N.A. Glyphosate perturbs the gut microbiota of honey bees. Proc. Natl. Acad. Sci. USA 2018, 115, 10305-10310. [CrossRef]

6. Iori, S.; Rovere, G.D.; Ezzat, L.; Smits, M.; Ferraresso, S.S.; Babbucci, M.; Marin, M.G.; Masiero, L.; Fabrello, J.; Garro, E.; et al. The effects of glyphosate and AMPA on the mediterranean mussel Mytilus galloprovincialis and its microbiota. Environ. Res. 2020, 182, 108984. [CrossRef]

7. Aris, A.; Leblanc, S. Maternal and fetal exposure to pesticides associated to genetically modified foods in Eastern Townships of Quebec, Canada. Reprod. Toxicol. 2011, 31, 528-533. [CrossRef]

8. Rahman, M.M.; Lee, D.J.; Jo, A.; Yun, S.H.; Eun, J.B.; Im, M.H.; Shim, J.H.; Abd El-Aty, A.M. Onsite/on-field analysis of pesticide and veterinary drug residues by a state-of-art technology: A review. J. Sep. Sci. 2021, 44, 2310-2327. [CrossRef] [PubMed]

9. Liu, B.; Dong, L.; Yu, Q.; Li, X.; Wu, F.; Tan, Z.; Luo, S. Thermodynamic Study on the Protonation Reactions of Glyphosate in Aqueous Solution: Potentiometry, Calorimetry and NMR spectroscopy. J. Phys. Chem. B 2016, 120, 2132-2137. [CrossRef]

10. Huhn, C. More and enhanced glyphosate analysis is needed. Anal. Bioanal. Chem. 2018, 410, 3041-3045. [CrossRef] [PubMed]

11. Okada, E.; Coggan, T.; Anumol, T.; Clarke, B.; Allinson, G. A simple and rapid direct injection method for the determination of glyphosate and AMPA in environmental water samples. Anal. Bioanal. Chem. 2019, 411, 715-724. [CrossRef]

12. Pinto, E.; Soares, A.G.; Ferreira, I.M.P.L.V.O. Quantitative analysis of glyphosate, glufosinate and AMPA in irrigation water by in situ derivatization-dispersive liquid-liquid microextraction combined with UPLC-MS/MS. Anal. Methods 2018, 10, 554-561. [CrossRef]

13. Prasad, B.B.; Jauhari, D.; Tiwari, M.P. Doubly imprinted polymer nanofilm-modified electrochemical sensor for ultra-trace simultaneous analysis of glyphosate and glufosinate. Biosens. Bioelectron. 2014, 59, 81-88. [CrossRef] [PubMed]

14. Minami, T.; Liu, Y.; Akdeniz, A.; Koutnik, P.; Esipenko, N.A.; Nishiyabu, R.; Kubo, Y.; Anzenbacher, P. Intramolecular Indicator Displacement Assay for Anions: Supramolecular Sensor for Glyphosate. J. Am. Chem. Soc. 2014, 136, 11396-11401. [CrossRef] [PubMed]

15. Bera, M.K.; Mohapatra, S. Ultrasensitive detection of glyphosate through effective photoelectron transfer between CdTe and chitosan derived carbon dot. Colloids Surf. A 2020, 596, 124710. [CrossRef] 
16. Wang, L.; Bi, Y.; Gao, J.; Li, Y.; Ding, H.; Ding, L. Carbon dots based turn-on fluorescent probes for the sensitive determination of glyphosate in environmental water samples. RSC Adv. 2016, 6, 85820-85828. [CrossRef]

17. Wang, D.; Lin, B.; Cao, Y.; Guo, M.; Yu, Y. A Highly Selective and Sensitive Fluorescence Detection Method of Glyphosate Based on an Immune Reaction Strategy of Carbon Dot Labeled Antibody and Antigen Magnetic Beads. J. Agric. Food Chem. 2016, 64, 6042-6050. [CrossRef] [PubMed]

18. Wang, L.; Bi, Y.; Hou, J.; Li, H.; Xu, Y.; Wang, B.; Ding, H.; Ding, L. Facile, green and clean one-step synthesis of carbon dots from wool: Application as a sensor for glyphosate detection based on the inner filter effect. Talanta 2016, 160, 268-275. [CrossRef] [PubMed]

19. Wang, X.; Yang, Y.; Huo, D.; Ji, Z.; Ma, Y.; Yang, M.; Luo, H.; Luo, X.; Hou, C.; Lv, J. A turn-on fluorescent nanoprobe based on N-doped silicon quantum dots for rapid determination of glyphosate. Microchim. Acta 2020, 187, 341. [CrossRef] [PubMed]

20. Sawetwong, P.; Chairam, S.; Jarujamrus, P.; Amatatongchai, M. Enhanced selectivity and sensitivity for colorimetric determination of glyphosate using Mn-ZnS quantum dot embedded molecularly imprinted polymers combined with a 3D-microfluidic paper-based analytical device. Talanta 2021, 225, 122077. [CrossRef] [PubMed]

21. Dasary, S.S.R.; Rai, U.S.; Yu, H.; Anjaneyulu, Y.; Dubey, M.; Ray, P.C. Gold nanoparticle based surface enhanced fluorescence for detection of organophosphorus agents. Chem. Phys. Lett. 2008, 460, 187-190. [CrossRef]

22. Lee, H.U.; Shin, H.Y.; Lee, J.Y.; Song, Y.S.; Park, C.; Kim, S.W. Quantitative Detection of Glyphosate by Simultaneous Analysis of UV Spectroscopy and Fluorescence Using DNA-Labeled Gold Nanoparticles. J. Agric. Food Chem. 2010, 58, 12096-12100. [CrossRef] [PubMed]

23. Li, H.; Chen, H.; Li, M.; Lu, Q.; Zhang, Y.; Yao, S. Template protection of gold nanoclusters for the detection of organophosphorus pesticides. New J. Chem. 2019, 43, 5423-5428. [CrossRef]

24. Cai, Y.; Zhu, H.; Zhou, W.; Qiu, Z.; Chen, C.; Qileng, A.; Li, K.; Liu, Y. Capsulation of AuNCs with AIE Effect into Metal-Organic Framework for the Marriage of a Fluorescence and Colorimetric Biosensor to Detect Organophosphorus Pesticides. Anal. Chem. 2021, 93, 7275-7282. [CrossRef]

25. Lee, H.U.; Jung, D.U.; Lee, J.H.; Song, Y.S.; Park, C.; Kim, S.W. Detection of glyphosate by quantitative analysis of fluorescence and single DNA using DNA-labeled fluorescent magnetic core-shell nanoparticles. Sens. Actuators, B 2013, 177, 879-886. [CrossRef]

26. Wang, M.; Ye, H.; You, L.; Chen, X. A Supramolecular Sensor Array Using Lanthanide-Doped Nanoparticles for Sensitive Detection of Glyphosate and Proteins. ACS Appl. Mater. Interfaces 2016, 8, 574-581. [CrossRef] [PubMed]

27. Rawat, K.A.; Majithiya, R.P.; Rohit, J.V.; Basu, H.; Singhal, R.K.; Kailasa, S.K. Mg2+ ion as a tuner for colorimetric sensing of glyphosate with improved sensitivity via the aggregation of 2-mercapto-5-nitrobenzimidazole capped silver nanoparticles. RSC Adv. 2016, 6, 47741-47752. [CrossRef]

28. Wu, D.; Sedgwick, A.C.; Gunnlaugsson, T.; Akkaya, E.U.; Yoon, J.; James, T.D. Fluorescent chemosensors: The past, present and future. Chem. Soc. Rev. 2017, 46, 7105-7123. [CrossRef] [PubMed]

29. Fu, Y.; Finney, N.S. Small-molecule fluorescent probes and their design. RSC Adv. 2018, 8, 29051-29061. [CrossRef]

30. Pouessel, J.; Abada, S.; Le Bris, N.; Elhabiri, M.; Charbonnière, L.J.; Tripier, R. A new bis-tetraamine ligand with a chromophoric 4-(9-anthracenyl)-2,6-dimethylpyridinyl linker for glyphosate and ATP sensing. Dalton Trans. 2013, 42, 4859-4872. [CrossRef]

31. Jenkins, A.L.; Yin, R.; Jensen, J.L. Molecularly imprinted polymer sensors for pesticide and insecticide detection in water. Analyst 2001, 126, 798-802. [CrossRef] [PubMed]

32. Guan, J.; Yang, J.; Zhang, Y.; Zhang, X.; Deng, H.; Xu, J.; Wang, J.; Yuan, M.-S. Employing a fluorescent and colorimetric picolyl-functionalized rhodamine for the detection of glyphosate pesticide. Talanta 2021, 224, 121834. [CrossRef] [PubMed]

33. Spangler, C.; Schaeferling, M.; Wolfbeis, O.S. Fluorescent probes for microdetermination of inorganic phosphates and biophosphates. Microchim. Acta 2008, 161, 1-39. [CrossRef]

34. McNaughton, D.A.; Fares, M.; Picci, G.; Gale, P.A.; Caltagirone, C. Advances in fluorescent and colorimetric sensors for anionic species. Coord. Chem. Rev. 2021, 427. [CrossRef]

35. Kubik, S. Anion recognition in water. Chem. Soc. Rev. 2010, 39, 3648-3663. [CrossRef] [PubMed]

36. Fitzmaurice, R.J.; Gaggini, F.; Srinivasan, N.; Kilburn, J.D. Carboxylate binding in polar solvents using pyridylguanidinium salts. Org. Biomol. Chem. 2007, 5, 1706-1714. [CrossRef] [PubMed]

37. Schmuck, C. Carboxylate Binding by 2-(Guanidiniocarbonyl)pyrrole Receptors in Aqueous Solvents: Improving the Binding Properties of Guanidinium Cations through Additional Hydrogen Bonds. Chem. Eur. J. 2000, 6, 709-718. [CrossRef]

38. Jiménez Blanco, J.L.; Bootello, P.; Benito, J.M.; Ortiz Mellet, C.; García Fernández, J.M. Urea-, Thiourea-, and Guanidine-Linked Glycooligomers as Phosphate Binders in Water. J. Org. Chem. 2006, 71, 5136-5143. [CrossRef] [PubMed]

39. Wan, W.; Wagner, S.; Rurack, K. Fluorescent monomers: "bricks" that make a molecularly imprinted polymer "bright". Anal. Bioanal. Chem. 2016, 408, 1753-1771. [CrossRef] [PubMed]

40. Gawlitza, K.; Wan, W.; Wagner, S.; Rurack, K. Fluorescent Molecularly Imprinted Polymers. In Advanced Molecularly Imprinting Materials; Tiwari, A., Uzun, L., Eds.; Wiley-Scrivener: Beverly, MA, USA, 2017; pp. 89-128. [CrossRef]

41. Puzio, K.; Claude, B.; Amalric, L.; Berho, C.; Grellet, E.; Bayoudh, S.; Nehmé, R.; Morin, P. Molecularly imprinted polymer dedicated to the extraction of glyphosate in natural waters. J. Chromatogr. A 2014, 1361, 1-8. [CrossRef] [PubMed]

42. Berho, C.; Claude, B.; Coisy, E.; Togola, A.; Bayoudh, S.; Morin, P.; Amalric, L. Laboratory calibration of a POCIS-like sampler based on molecularly imprinted polymers for glyphosate and AMPA sampling in water. Anal. Bioanal. Chem. 2017, 409, $2029-2035$. [CrossRef] [PubMed] 
43. Zhang, C.; She, Y.; Li, T.; Zhao, F.; Jin, M.; Guo, Y.; Zheng, L.; Wang, S.; Jin, F.; Shao, H.; et al. A highly selective electrochemical sensor based on molecularly imprinted polypyrrole-modified gold electrode for the determination of glyphosate in cucumber and tap water. Anal. Bioanal. Chem. 2017, 409, 7133-7144. [CrossRef] [PubMed]

44. Zouaoui, F.; Bourouina-Bacha, S.; Bourouina, M.; Abroa-Nemeir, I.; Ben Halima, H.; Gallardo-Gonzalez, J.; El Alami El Hassani, N.; Alcacer, A.; Bausells, J.; Jaffrezic-Renault, N.; et al. Electrochemical impedance spectroscopy determination of glyphosate using a molecularly imprinted chitosan. Sens. Actuators, B 2020, 309, 127753. [CrossRef]

45. Valderrey, V.; Gawlitza, K.; Rurack, K. Thiourea- and Amino-substituted Benzoxadiazole Dyes with Large Stokes Shifts as Red-emitting Probe Monomers for Imprinted Polymer Layers Targeting Carboxylate-containing Antibiotics. Chem. Eur. J. 2022, 28. [CrossRef] [PubMed]

46. Wan, W.; Descalzo, A.B.; Shinde, S.; Weißhoff, H.; Orellana, G.; Sellergren, B.; Rurack, K. Ratiometric Fluorescence Detection of Phosphorylated Amino Acids Through Excited-State Proton Transfer by Using Molecularly Imprinted Polymer (MIP) Recognition Nanolayers. Chem. Eur. J. 2017, 23, 15974-15983. [CrossRef] [PubMed]

47. Schneider, C.A.; Rasband, W.S.; Eliceiri, K.W. NIH Image to ImageJ: 25 years of image analysis. Nat. Methods 2012, 9, 671-675. [CrossRef] [PubMed]

48. Wan, W.; Biyikal, M.; Wagner, R.; Sellergren, B.; Rurack, K. Fluorescent Sensory Microparticles that "Light-up" Consisting of a Silica Core and a Molecularly Imprinted Polymer (MIP) Shell. Angew. Chem. Int. Ed. 2013, 52, 7023-7027. [CrossRef]

49. Horváth, P.; Šebej, P.; Šolomek, T.; Klán, P. Small-Molecule Fluorophores with Large Stokes Shifts: 9-Iminopyronin Analogues as Clickable Tags. J. Org. Chem. 2015, 80, 1299-1311. [CrossRef]

50. Lakowicz, J.R. Conversion Between Wavelength and Wavenumber. In Principles of Fluorescence Spectroscopy, 3rd ed.; Springer: Singapore, 2006; Chapter 2.9.4; pp. 53-54.

51. Blondeau, P.; Segura, M.; Pérez-Fernández, R.; de Mendoza, J. Molecular recognition of oxoanions based on guanidinium receptors. Chem. Soc. Rev. 2007, 36, 198-210. [CrossRef] [PubMed]

52. Dietrich, B.; Fyles, T.M.; Lehn, J.-M.; Pease, L.G.; Fyles, D.L. Anion receptor molecules. Synthesis and some anion binding properties of macrocyclic guanidinium salts. J. Chem. Soc. Chem. Commun. 1978, 934-936. [CrossRef]

53. Houk, R.J.T.; Tobey, S.L.; Anslyn, E.V. Abiotic Guanidinium Receptors for Anion Molecular Recognition and Sensing. In Anion Sensing; Stibor, I., Ed.; Springer: Berlin/Heidelberg, Germany, 2005; pp. 199-229. [CrossRef]

54. Tobey, S.L.; Anslyn, E.V. Energetics of Phosphate Binding to Ammonium and Guanidinium Containing Metallo-Receptors in Water. J. Am. Chem. Soc. 2003, 125, 14807-14815. [CrossRef] [PubMed]

55. Peixoto, M.M.; Bauerfeldt, G.F.; Herbst, M.H.; Pereira, M.S.; da Silva, C.O. Study of the Stepwise Deprotonation Reactions of Glyphosate and the Corresponding pKa Values in Aqueous Solution. J. Phys. Chem. A 2015, 119, 5241-5249. [CrossRef] [PubMed]

56. Brynn Hibbert, D.; Thordarson, P. The death of the Job plot, transparency, open science and online tools, uncertainty estimation methods and other developments in supramolecular chemistry data analysis. Chem. Commun. 2016, 52, 12792-12805. [CrossRef]

57. Rurack, K.; Radeglia, R. Transition Metal Ion Complexes of 2,2'-Bipyridyl-3,3'-diol and 2,2'-Bipyridyl-3-ol: Spectroscopic Properties and Solvent-Dependent Binding Modes. Eur. J. Inorg. Chem. 2000, 2000, 2271-2282. [CrossRef]

58. Thordarson, P. Determining association constants from titration experiments in supramolecular chemistry. Chem. Soc. Rev. 2011, 40, 1305-1323. [CrossRef] [PubMed]

59. Wulff, G.; Knorr, K. Stoichiometric noncovalent interaction in molecular imprinting. Bioseparation 2001, 10, 257-276. [CrossRef] [PubMed]

60. Wagner, S.; Bell, J.; Biyikal, M.; Gawlitza, K.; Rurack, K. Integrating fluorescent molecularly imprinted polymer (MIP) sensor particles with a modular microfluidic platform for nanomolar small-molecule detection directly in aqueous samples. Biosens. Bioelectron. 2018, 99, 244-250. [CrossRef] [PubMed]

61. Kimani, M.; Beyer, S.; El-Schich, Z.; Gawlitza, K.; Gjörloff-Wingren, A.; Rurack, K. Imprinted Particles for Direct Fluorescence Detection of Sialic Acid in Polar Media and on Cancer Cells with Enhanced Control of Nonspecific Binding. ACS Appl. Polym. Mater. 2021, 3, 2363-2373. [CrossRef]

62. Chadha, R.N.; Shukla, J.S.; Misra, G.S. Studies in chain-transfer. Part 2.-Catalyzed polymerization of methyl methacrylate. Trans. Faraday Soc. 1957, 53, 240-246. [CrossRef]

63. Tsujii, Y.; Ejaz, M.; Sato, K.; Goto, A.; Fukuda, T. Mechanism and Kinetics of RAFT-Mediated Graft Polymerization of Styrene on a Solid Surface. 1. Experimental Evidence of Surface Radical Migration. Macromolecules 2001, 34, 8872-8878. [CrossRef]

64. di Nunzio, M.R.; Perenlei, G.; Douhal, A. Confinement Effect of Micro- and Mesoporous Materials on the Spectroscopy and Dynamics of a Stilbene Derivative Dye. Int. J. Mol. Sci. 2019, 20, 1316. [CrossRef] [PubMed]

65. Armbruster, D.A.; Pry, T. Limit of blank, limit of detection and limit of quantitation. Clin. Biochem. Rev. 2008, 29 (Suppl. 1), S49-S52.

66. Evaluation of Measurement Data-Guide to the Expression of Uncertainty in Measurement. JCGM 100:2008. Joint Committee for Guides in Metrology (JCGM), 2008; p. 134. Available online: https://www.bipm.org/documents/20126/2071204/JCGM_100_20 08_E.pdf/cb0ef43f-baa5-11cf-3f85-4dcd86f77bd6 (accessed on 25 October 2021).

67. Rurack, K.; Spieles, M. Fluorescence Quantum Yields of a Series of Red and Near-Infrared Dyes Emitting at 600-1000 nm. Anal. Chem. 2011, 83, 1232-1242. [CrossRef] [PubMed]

68. Glyphosate and AMPA in Drinking Water. World Health Organization, 2005. Available online: https://www.who.int/water sanitation_health/dwq/chemicals/glyphosateampa290605.pdf (accessed on 25 October 2021). 